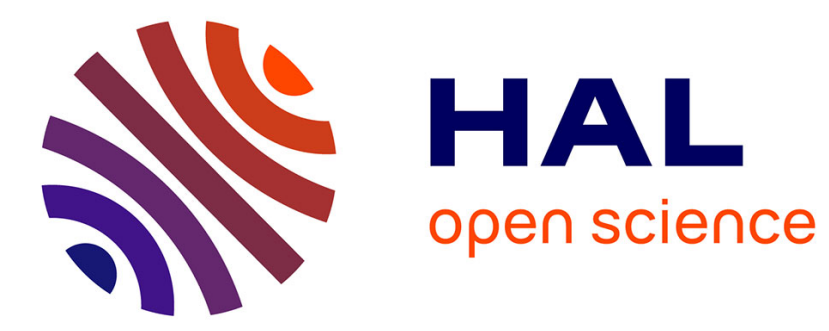

\title{
An energy dependent phase shift analysis of proton-proton scattering between 700 and $1300 \mathrm{MeV}$
}

\author{
F. Lehar, C. Lechanoine-Leluc, J. Bystricky
}

\section{To cite this version:}

F. Lehar, C. Lechanoine-Leluc, J. Bystricky. An energy dependent phase shift analysis of protonproton scattering between 700 and $1300 \mathrm{MeV}$. Journal de Physique, 1987, 48 (8), pp.1273-1290. 10.1051/jphys:019870048080127300 . jpa-00210553

\section{HAL Id: jpa-00210553 https://hal.science/jpa-00210553}

Submitted on 1 Jan 1987

HAL is a multi-disciplinary open access archive for the deposit and dissemination of scientific research documents, whether they are published or not. The documents may come from teaching and research institutions in France or abroad, or from public or private research centers.
L'archive ouverte pluridisciplinaire HAL, est destinée au dépôt et à la diffusion de documents scientifiques de niveau recherche, publiés ou non, émanant des établissements d'enseignement et de recherche français ou étrangers, des laboratoires publics ou privés. 


\title{
An energy dependent phase shift analysis of proton-proton scattering between 700 and $1300 \mathrm{MeV}$
}

\author{
F. Lehar, C. Lechanoine-Leluc $\left({ }^{+}\right)$and J. Bystricky $\left({ }^{a}, *\right)$ \\ DPhPE, CEN-Saclay, 91191 Gif sur Yvette, Cedex, France \\ $\left({ }^{+}\right)$DPNC, Université de Genève, Geneva, Switzerland \\ (*) UCLA, Los Angeles, California 90024, U.S.A.
}

(Reçu le 17 décembre 1986, révisé le 16 mars 1987, accepté le 2 avril 1987)

\begin{abstract}
Résumé. - Une analyse en déphasages avec dépendance en énergie est présentée pour la réaction élastique $\mathrm{pp} \Rightarrow \mathrm{pp}$ entre 700 et $1300 \mathrm{MeV}$. La plupart des déphasages se connectent parfaitement avec ceux trouvés dans l'analyse de Saclay-Genève en dessous de $800 \mathrm{MeV}$. Grâce aux nouveaux résultats de Saturne II, la base de données est maintenant suffisante pour faire une telle analyse. Par contre nos résultats sont en désaccord avec ceux trouvés par Arndt et al., et ce pour la plupart des déphasages. Le comportement des diagrammes d'Argand suggère un comportement résonnant pour l'onde partielle ${ }^{1} \mathrm{G}_{4}$ mais pas pour l'onde ${ }^{3} \mathrm{~F}_{3}$.

Abstract. - An energy dependent $\mathrm{pp} \Rightarrow$ pp phase-shift analysis for elastic proton-proton scattering is reported in the energy range between 700 to $1300 \mathrm{MeV}$. Almost all phase shifts smoothly connect with the previous results of the Saclay-Geneva phase shift analysis below $800 \mathrm{MeV}$. Due to recent Saturne II results the data base is now sufficiently abundant to perform such an analysis. Present results strongly disagree with the predictions of Arndt et al., for most phase shifts. Argand diagrams suggest a non-resonant behaviour of the ${ }^{3} \mathrm{~F}_{3}$ partial wave and a resonance-like behaviour for the ${ }^{1} \mathrm{G}_{4}$ partial wave.
\end{abstract}

\section{Introduction.}

We present an energy dependent phase shift analysis (PSA) of elastic pp scattering in the energy range from 700 to $1300 \mathrm{MeV}$. It makes use of a reasonable number of different spin observables measured with a good precision in a large angular domain. The PSA was made possible by the recent results obtained at Saturne II which have considerably enlarged the existing data base. This PSA is an extension and confirmation of the Saclay-Geneva PSA [1] in the energy range from 10 to $800 \mathrm{MeV}$. With the exception of the narrow energy interval between 970 and $1040 \mathrm{MeV}$, the data base above $800 \mathrm{MeV}$ up to now has been too sparse to perform even fixed energy analysis.

The Arndt et al. [3, 4] energy dependent PSA from 0 to $1.1 \mathrm{GeV}$ differs considerably from the present PSA results for almost all phase shifts. Note that it makes use of an insufficient data base above $800 \mathrm{MeV}$, except around $1 \mathrm{GeV}$.

There exist also several other fixed energy PSA

( $^{a}$ Permanent address : DPhPE, CEN-Saclay, France. above $800 \mathrm{MeV}$. All of them have quite insufficient data base and their results are very dispersed.

The present PSA uses the same amplitude formalism, one pion exchange (OPE) contributions, electromagnetic contributions and a phase shift energy dependence as described in reference [1]. These subjects are briefly reviewed in section 2 , while section 3 is devoted to the data base. Results, their discussion and comparison with other representative analyses [3-8] and with the Paris potential predictions $[9,10]$ are presented in section 4 . Conclusions are summarized in section 5 .

Throughout this article we will use a four-index notation and the formalism presented in reference [11]. For data published before April 1981 we refer to reference [2] (reference to data already included in Ref. [2] are quoted as in Ref. [2] e.g. 78/B-200).

\section{Formalism.}

The observables are expressed in terms of five complex scattering amplitudes, the invariant scattering amplitudes $a, b, c, d$ and $e$, as discussed in 
reference [11]. The angular dependence of the amplitudes is expressed by Legendre polynomial series and partial wave amplitudes $\alpha_{L J}$ (Ref. [12] and formulae (2), (3) in Ref. [1]). Partial wave amplitudes, parametrized by nuclear bar phase shifts $\delta_{L J}$ are real, while at higher energies the $\delta_{L J}$ can be complex with $\operatorname{Im} \delta \geq 0$. As in reference [1] we use the «five parameter representation » for the partial wave amplitudes assuming all $\varepsilon_{J}$ to be real. This is justified by the fact that the fit to the data is reasonably good and that the number of imaginary phase shifts increases little compared to the lower energy interval. Indeed, only $\operatorname{Im}{ }^{1} \mathrm{~S}_{0}, \operatorname{Im}{ }^{3} \mathrm{P}_{1}$ and . $\mathrm{Im}^{3} \mathrm{H}_{5}$ were added at high energies to the imaginary parts of the ${ }^{3} \mathrm{P}_{2},{ }^{1} \mathrm{D}_{2},{ }^{3} \mathrm{~F}_{2},{ }^{3} \mathrm{~F}_{3}$ and ${ }^{1} \mathrm{G}_{4}$ phase shifts used below $800 \mathrm{MeV}$ in reference [1]. Other phase shift analyses in this energy range also use five parameters.

The expansion of the amplitudes was truncated at the total angular momentum $J_{\max }$ and orbital angular momentum $L_{\max }$. The higher angular momentum states were replaced, as usual, by the Born approximation of the OPE contribution (Refs. [13, 14] and formulae (4) in Ref. [1]).

The Coulomb amplitudes and Coulomb-nuclear interferences were introduced as in references [12, 14]. For angular momenta $L$ higher than $L_{\max }$, we have added the magnetic moment correction [15] to the amplitude $e$.

The energy dependence of the phase shifts were fitted by a polynomial expansion of the form

$$
\sum_{n=0}^{3} \frac{a_{L V n}}{n !}\left(T-T_{0}\right)^{n}
$$

where $T_{0}$ is the central point of the interval (1 $000 \mathrm{MeV}$ for the present PSA) and $a_{L J n}$ are variable parameters. In all cases it turned out that $n=3$ was sufficient (for seven real phase shifts), and in some cases we adopted $n=2, n=1$ or $n=0$. Proper threshold behaviour was assured by multiplying equation (1) by the OPE contributions, obtained from the appropriately calculated OPE elements of the $K$-matrix. The higher waves, as mentioned above, were taken to be pure OPE ones. It is well known that low- $L$ OPE phase shifts do not correspond to the nuclear-bar phase shifts. We have therefore used the scattering length and effective range energy dependence for ${ }^{1} S_{0}$ phase shift.

The energy dependence of the imaginary parts of phase shifts are parametrized as

$$
\begin{aligned}
& \operatorname{Im} \delta_{L J}(T)=
\end{aligned}
$$

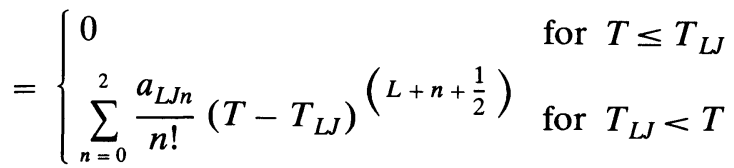

where the threshold energy $T_{L J}$ is proper to each phase shift. It was fixed by the value found in the previous PSA if the imaginary part of a given phase shift was non-zero. For $\operatorname{Im}{ }^{1} \mathrm{~S}_{0}$ and $\operatorname{Im}{ }^{3} \mathrm{P}_{1}$ phase shifts the corresponding $T_{L J}$ were treated as free parameters. The coefficients $a_{L J 0}, a_{L J 1}$ and $a_{L J 2}$ were varied. The parametrization, equation (2), of the threshold behaviour of the imaginary parts of the phase shifts is in agreement with general analyticity and unitarity requirements. Inelastic unitarity was imposed by constraining the $\operatorname{Im} \delta_{L J}$ to be nonnegative.

\section{Data base.}

3.1 AnAlysed DATA. - To denote the experimental quantities, we use a four subscript notation [11] $X_{\text {srbt }}$, where the subscripts, s, r, b, t refer to the scattered, recoil, beam and target particle spin orientation, respectively.

In the present analysis we have used all the relevant data available in the compilation of reference [2] as well as recently published data. These latter are listed in table I (Refs. [16-48]). Some data from different experiments at Saturne II, included in this PSA, have only recently been submitted for publication.

A total of 4356 independent pp data points were analysed. A more detailed repartition of the data is shown in table II. For each type of experiment the total number of data points as well as their occurrences is indicated.

3.2 InElastic TOTAL CROSS-SECTIONS. - The inelastic total cross-sections were introduced in the PSA as described in reference [1]. We have fitted the energy dependence of the total cross-section of the reaction $j$ by an expression of the form [49] :

$$
\sigma_{j}(T)=\left(T-T_{\mathrm{oj}}\right) \exp \left[\sum_{i=0}^{n} c_{i j} P_{i}(T)\right],
$$

where $P_{i}$ are polynomials of the energy $T$ and the parameters $T_{\mathrm{o} j}, c_{\mathrm{o} j}, \ldots, c_{n j}$ are fitted for each reaction $j$. The total inelastic cross-section was then calculated as a sum of all the reaction cross-sections, fitted together with the independent measurements of the $\sigma_{\text {tot }}$ (inelastic). The $\sigma_{\text {tot }}$ (inelastic) were introduced into the PSA in $5 \mathrm{MeV}$ steps with the calculated errors. Our fitted pp reaction cross-section is in good agreement with the one obtained by VerWest and Arndt [50] up to $750 \mathrm{MeV}$. From there on, the $2 \pi$-channel contributions, not taken into account in reference [50], become significant, representing $\sim 3 \mathrm{mb}$ at $1300 \mathrm{MeV}$. Our treatment of total inelastic cross sections is discussed in a separate article (see Ref. [49b]). 
Table I. - Recent pp measurements from 1981 to 1986.

\begin{tabular}{|c|c|c|c|c|c|}
\hline Observable & $\begin{array}{c}\text { Kin. Energy Range } \\
(\mathrm{MeV})\end{array}$ & $\begin{array}{l}\text { Angular Range } \\
\text { CM deg. }\end{array}$ & \begin{tabular}{|l|} 
Total \\
Points
\end{tabular} & Accelerator & Ref. \\
\hline$\sigma_{\text {tot }}$ & $767-1260$ & 0 & 5 & KEK & [16] \\
\hline$\sigma_{\text {tot }}(\mathrm{el})$ & $767-1260$ & 0 & 5 & KEK & [16] \\
\hline$\Delta \sigma_{T}$ & $\begin{array}{c}702-1220 \\
791 \\
741-791 \\
730-1271\end{array}$ & $\begin{array}{l}0 \\
0 \\
0 \\
0\end{array}$ & $\begin{array}{r}12 \\
1 \\
2 \\
4\end{array}$ & $\begin{array}{l}\text { Saturne II } \\
\text { LAMPF } \\
\text { LAMPF } \\
\text { ZGS-ANL }\end{array}$ & $\begin{array}{l}{[17]} \\
{[18]} \\
{[19]} \\
{[19]}\end{array}$ \\
\hline$\Delta \sigma_{L}$ & $\begin{array}{l}739-790 \\
752-1293\end{array}$ & $\begin{array}{l}0 \\
0\end{array}$ & $\begin{array}{l}3 \\
5\end{array}$ & $\begin{array}{l}\text { LAMPF } \\
\text { Saturne II }\end{array}$ & $\begin{array}{l}{[20]} \\
{[21]}\end{array}$ \\
\hline $\mathrm{d} \sigma / \mathrm{d} \Omega$ & $\begin{array}{cc}746 \\
795 \\
843 \\
892 \\
942 \\
992 \\
992 \\
699-1203 \\
797 \\
797 \\
800 \\
857 \\
11078 \\
1168 \\
1168 \\
11262\end{array}$ & $\begin{array}{c}7.1-17.3 \\
8.0-17.5 \\
6.8-17.2 \\
7.2-17.3 \\
6.9-16.6 \\
6.5-16.7 \\
3.7-8.0 \\
90 \\
2.9-10.3 \\
1.2-11.4 \\
5.9-91 \\
22.3-88.6 \\
22.3-88.6 \\
22.3-88.6 \\
22.3-88.6 \\
22.3-88.6\end{array}$ & $\begin{array}{l}25 \\
23 \\
25 \\
24 \\
23 \\
24 \\
39 \\
86 \\
45 \\
41 \\
70 \\
19 \\
19 \\
19 \\
19 \\
19\end{array}$ & $\begin{array}{l}\text { Gatchina } \\
\text { Gatchina } \\
\text { Gatchina } \\
\text { Gatchina } \\
\text { Gatchina } \\
\text { Gatchina } \\
\text { Gatchina } \\
\text { Saturne II } \\
\text { LAMPF } \\
\text { LAMPF } \\
\text { LAMPF } \\
\text { KEK } \\
\text { KEK } \\
\text { KEK } \\
\text { KEK } \\
\text { KEK }\end{array}$ & $\begin{array}{l}{[22]} \\
{[22]} \\
{[22]} \\
{[22]} \\
{[22]} \\
{[22]} \\
{[23]} \\
{[24]} \\
{[25]} \\
{[25]} \\
{[26]} \\
{[27]} \\
{[27]} \\
{[27]} \\
{[27]} \\
{[27]}\end{array}$ \\
\hline$A_{\text {oono }}$ & $\begin{array}{c}699 \\
750 \\
699-800 \\
797 \\
800 \\
800 \\
800 \\
699-1015 \\
702 \\
720 \\
720 \\
790 \\
790 \\
834 \\
874 \\
934 \\
995 \\
1095 \\
719 \\
719 \\
894 \\
1145 \\
874 \\
870 \\
1095 \\
1091 \\
1295\end{array}$ & $\begin{array}{c}34.6-123.0 \\
34.6-122.8 \\
\sim 40 \\
1.2-14.0 \\
10.4-47.0 \\
40.1-47.0 \\
14.3-75.4 \\
35-88 \\
42.2-77.7 \\
42.3-77.7 \\
42.2-81.7 \\
40.2-77.6 \\
40.2-77.6 \\
43.0-86.6 \\
42.8-86.8 \\
42.8-86.9 \\
42.9-86.9 \\
43.4-87.0 \\
46.6-86.1 \\
53.6-88.7 \\
57.2-88.9 \\
59.3-91.7 \\
28.6-47.9 \\
30.0-47.9 \\
28.3-53.5 \\
26.8-52.5 \\
28.6-55.6\end{array}$ & $\begin{array}{r}9 \\
8 \\
3 \\
35 \\
9 \\
4 \\
14 \\
1050 \\
19 \\
19 \\
20 \\
20 \\
20 \\
23 \\
23 \\
23 \\
23 \\
23 \\
21 \\
19 \\
17 \\
17 \\
11 \\
5 \\
14 \\
8 \\
15\end{array}$ & $\begin{array}{l}\text { LAMPF } \\
\text { LAMPF } \\
\text { LAMPF } \\
\text { LAMPF } \\
\text { LAMPF } \\
\text { LAMPF } \\
\text { LAMPF } \\
\text { Saturne II } \\
\text { Saturne II } \\
\text { Saturne II } \\
\text { Saturne II } \\
\text { Saturne II } \\
\text { Saturne II } \\
\text { Saturne II } \\
\text { Saturne II } \\
\text { Saturne II } \\
\text { Saturne II } \\
\text { Saturne II } \\
\text { Saturne II } \\
\text { Saturne II } \\
\text { Saturne II } \\
\text { Saturne II } \\
\text { Saturne II } \\
\text { Saturne II } \\
\text { Saturne II } \\
\text { Saturne II } \\
\text { Saturne II }\end{array}$ & $\begin{array}{l}{[28]} \\
{[28]} \\
{[29]} \\
{[25]} \\
{[26]} \\
{[26]} \\
{[26]} \\
{[30]} \\
{[31]} \\
{[31]} \\
{[31]} \\
{[31]} \\
{[31]} \\
{[32]} \\
{[32]} \\
{[32]} \\
{[32]} \\
{[32]} \\
{[33]} \\
{[33]} \\
{[33]} \\
{[33]} \\
{[34]} \\
{[34]} \\
{[34]} \\
{[34]} \\
{[34]}\end{array}$ \\
\hline
\end{tabular}


Table I (continued).

\begin{tabular}{|c|c|c|c|c|c|}
\hline Observable & $\begin{array}{c}\text { Kin. Energy Range } \\
(\mathrm{MeV})\end{array}$ & $\begin{array}{l}\text { Angular Range } \\
\text { CM deg. }\end{array}$ & $\begin{array}{l}\text { Total } \\
\text { Points }\end{array}$ & Accelerator & Ref. \\
\hline$A_{\text {oono }}$ & $\begin{array}{c}1292 \\
1295 \\
874 \\
890 \\
950 \\
761-950 \\
804\end{array}$ & $\begin{array}{c}29.9-52.7 \\
52.5-90.7 \\
50-85 \\
27.6-88.0 \\
35-70 \\
50 \\
50,85\end{array}$ & $\begin{array}{r}7 \\
20 \\
8 \\
13 \\
6 \\
8 \\
3\end{array}$ & $\begin{array}{l}\text { Saturne II } \\
\text { Saturne II } \\
\text { Saturne II } \\
\text { Gatchina } \\
\text { Gatchina } \\
\text { Gatchina } \\
\text { Gatchina }\end{array}$ & $\begin{array}{l}{[34]} \\
{[34]} \\
{[35]} \\
{[36]} \\
{[37]} \\
{[38]} \\
{[38]}\end{array}$ \\
\hline$D=D_{\text {nопо }}$ & $\begin{array}{c}741-790 \\
800 \\
800 \\
800 \\
800 \\
850 \\
900\end{array}$ & $\begin{array}{c}90 \\
4.8-23.8 \\
27.3-133.6 \\
23.8-69.2 \\
70-110 \\
50-130 \\
50-130\end{array}$ & $\begin{array}{r}2 \\
4 \\
11 \\
4 \\
3 \\
9 \\
9\end{array}$ & $\begin{array}{l}\text { LAMPF } \\
\text { LAMPF } \\
\text { LAMPF } \\
\text { LAMPF } \\
\text { Gatchina } \\
\text { Gatchina } \\
\text { Gatchina }\end{array}$ & $\begin{array}{l}{[39]} \\
{[40]} \\
{[41]} \\
{[28]} \\
{[42]} \\
{[42]} \\
{[42]}\end{array}$ \\
\hline$R=D_{s^{\prime} \text { oso }}$ & $\begin{array}{l}699 \\
750 \\
800 \\
800\end{array}$ & $\begin{array}{c}41.9-123.3 \\
42.3-134.0 \\
4.8-23.8 \\
21.2-133.6\end{array}$ & $\begin{array}{r}7 \\
7 \\
4 \\
12\end{array}$ & $\begin{array}{l}\text { LAMPF } \\
\text { LAMPF } \\
\text { LAMPF } \\
\text { LAMPF }\end{array}$ & $\begin{array}{l}{[28]} \\
{[28]} \\
{[40]} \\
{[41]}\end{array}$ \\
\hline$A=D_{s^{\prime} \mathrm{o} k \mathrm{o}}$ & $\begin{array}{l}699 \\
750 \\
800 \\
800 \\
874\end{array}$ & $\begin{array}{c}41.1-123.3 \\
42.3-134.0 \\
4.8-23.8 \\
21.2-133.6 \\
95-130\end{array}$ & $\begin{array}{r}8 \\
7 \\
3 \\
12 \\
8\end{array}$ & $\begin{array}{l}\text { LAMPF } \\
\text { LAMPF } \\
\text { LAMPF } \\
\text { LAMPF } \\
\text { Saturne II }\end{array}$ & $\begin{array}{l}{[28]} \\
{[28]} \\
{[40]} \\
{[41]} \\
{[35]}\end{array}$ \\
\hline$R^{\prime}=D_{k^{\prime} \text { oso }}$ & $\begin{array}{l}800 \\
800\end{array}$ & $\begin{array}{c}4.8-23.8 \\
18.8-133.1\end{array}$ & $\begin{array}{r}4 \\
11\end{array}$ & $\begin{array}{l}\text { LAMPF } \\
\text { LAMPF }\end{array}$ & $\begin{array}{l}{[40]} \\
{[28]}\end{array}$ \\
\hline$A^{\prime}=D_{k^{\prime} \text { oko }}$ & $\begin{array}{l}699 \\
750 \\
800 \\
800\end{array}$ & $\begin{array}{c}34.6-123.3 \\
34.6-134.0 \\
7.2-23.8 \\
18.8-133.1\end{array}$ & $\begin{array}{r}8 \\
8 \\
3 \\
11\end{array}$ & $\begin{array}{l}\text { LAMPF } \\
\text { LAMPF } \\
\text { LAMPF } \\
\text { LAMPF }\end{array}$ & $\begin{array}{l}{[28]} \\
{[28]} \\
{[40]} \\
{[28]}\end{array}$ \\
\hline$A_{\text {oonn }}$ & $\begin{array}{c}760-950 \\
890 \\
950 \\
700-800 \\
800 \\
702 \\
720 \\
790 \\
834 \\
874 \\
874 \\
934 \\
995 \\
1095 \\
1095 \\
1295 \\
1295\end{array}$ & $\begin{array}{c}50,90 \\
27.6-88.0 \\
35.0-98.0 \\
90 \\
5.7-37.0 \\
42.2-77.7 \\
42.3-77.7 \\
40.2-77.6 \\
43.0-86.6 \\
28.6-47.9 \\
42.8-86.8 \\
42.8-86.9 \\
42.9-86.9 \\
28.3-52.0 \\
43.4-87.0 \\
28.6-55.6 \\
52.5-90.7\end{array}$ & $\begin{array}{r}10 \\
13 \\
12 \\
3 \\
23 \\
19 \\
19 \\
20 \\
23 \\
11 \\
23 \\
23 \\
23 \\
13 \\
23 \\
15 \\
20\end{array}$ & $\begin{array}{l}\text { Gatchina } \\
\text { Gatchina } \\
\text { Gatchina } \\
\text { LAMPF } \\
\text { LAMPF } \\
\text { Saturne II } \\
\text { Saturne II } \\
\text { Saturne II } \\
\text { Saturne II } \\
\text { Saturne II } \\
\text { Saturne II } \\
\text { Saturne II } \\
\text { Saturne II } \\
\text { Saturne II } \\
\text { Saturne II } \\
\text { Saturne II } \\
\text { Saturne II }\end{array}$ & $\begin{array}{l}{[38]} \\
{[36]} \\
{[37]} \\
{[43]} \\
{[44]} \\
{[31]} \\
{[31]} \\
{[31]} \\
{[32]} \\
{[45]} \\
{[32]} \\
{[32]} \\
{[32]} \\
{[45]} \\
{[32]} \\
{[45]} \\
{[45]}\end{array}$ \\
\hline
\end{tabular}


Table I (continued).

\begin{tabular}{|c|c|c|c|c|c|}
\hline Observable & $\begin{array}{c}\text { Kin. Energy Range } \\
(\mathrm{MeV})\end{array}$ & $\begin{array}{l}\text { Angular Range } \\
\text { CM deg. }\end{array}$ & $\begin{array}{l}\text { Total } \\
\text { Points }\end{array}$ & Accelerator & Ref. \\
\hline$A_{\mathrm{ookk}}$ & $\begin{array}{r}706 \\
740 \\
790 \\
800 \\
806 \\
823 \\
1012 \\
1271 \\
719 \\
834 \\
874 \\
874 \\
934 \\
995 \\
1095 \\
1095 \\
1295\end{array}$ & $\begin{array}{c}26.5-50.5 \\
80-98 \\
80-98 \\
4.5-36.3 \\
29.5-50.5 \\
29.5-50.5 \\
29.5-53.5 \\
29.5-50.5 \\
49.6-87.6 \\
47.5-88.5 \\
34.5-51.9 \\
47.5-88.6 \\
46.7-89.5 \\
46.8-89.6 \\
30.5-55.9 \\
44.7-89.7 \\
28.6-93.0\end{array}$ & $\begin{array}{r}9 \\
10 \\
10 \\
25 \\
8 \\
8 \\
9 \\
8 \\
11 \\
22 \\
10 \\
22 \\
23 \\
23 \\
14 \\
23 \\
35\end{array}$ & $\begin{array}{l}\text { ANL-ZGS } \\
\text { LAMPF } \\
\text { LAMPF } \\
\text { LAMPF } \\
\text { ANL-ZGS } \\
\text { ANL-ZGS } \\
\text { ANL-ZGS } \\
\text { ANL-ZGS } \\
\text { Saturne II } \\
\text { Saturne II } \\
\text { Saturne II } \\
\text { Saturne II } \\
\text { Saturne II } \\
\text { Saturne II } \\
\text { Saturne II } \\
\text { Saturne II } \\
\text { Saturne II }\end{array}$ & $\begin{array}{l}{[46]} \\
{[20]} \\
{[20]} \\
{[44]} \\
{[46]} \\
{[46]} \\
{[46]} \\
{[46]} \\
{[47]} \\
{[47]} \\
{[48]} \\
{[47]} \\
{[47]} \\
{[47]} \\
{[48]} \\
{[47]} \\
{[48]}\end{array}$ \\
\hline$A_{\text {oosk }}$ & $\begin{array}{r}706 \\
806 \\
823 \\
874 \\
1012 \\
1271\end{array}$ & $\begin{array}{l}29.5-47.5 \\
29.5-50.5 \\
29.5-50.5 \\
50.4-89.4 \\
29.5-50.5 \\
29.5-50.5\end{array}$ & $\begin{array}{r}7 \\
8 \\
8 \\
21 \\
8 \\
8\end{array}$ & $\begin{array}{l}\text { ANL-ZGS } \\
\text { ANL-ZGS } \\
\text { ANL-ZGS } \\
\text { Saturne II } \\
\text { ANL-ZGS } \\
\text { ANL-ZGS }\end{array}$ & $\begin{array}{l}{[46]} \\
{[46]} \\
{[46]} \\
{[47]} \\
{[46]} \\
{[46]}\end{array}$ \\
\hline$N_{\text {onkk }}$ & 874 & $50-85$ & 8 & Saturne II & [35] \\
\hline
\end{tabular}

Table II. - Summary of pp data points between 700 and $1300 \mathrm{MeV}$ used in PSA.

\begin{tabular}{|c|c|c|}
\hline \multirow{2}{*}{$\begin{array}{c}\text { Experimental } \\
\text { Quantity }\end{array}$} & \multicolumn{2}{|c|}{$697-1300 \mathrm{MeV}$} \\
\hline & $\begin{array}{c}\text { Number of } \\
\text { Points }\end{array}$ & Percent \\
\hline $\begin{array}{l}\sigma_{\text {tot }} \\
\sigma_{\text {tot }}(\mathrm{el}) \\
\sigma_{\text {tot }}(\text { inel })\end{array}$ & $\begin{array}{r}108 \\
9 \\
32\end{array}$ & 3.4 \\
\hline $\begin{array}{l}\Delta \sigma_{T} \\
\Delta \sigma_{L}\end{array}$ & $\begin{array}{l}21 \\
11\end{array}$ & 0.7 \\
\hline $\mathrm{d} \sigma / \mathrm{d} \Omega$ & 1292 & 29.7 \\
\hline$A_{\mathrm{oono}}$ & 1906 & 43.8 \\
\hline $\begin{array}{l}D=D_{\text {nono }} \\
R=D_{s^{\prime} \text { oso }} \\
A=D_{s^{\prime} \text { oo }} \\
R^{\prime}=D_{k^{\prime} \text { oso }} \\
A^{\prime}=D_{k^{\prime} \text { oko }}\end{array}$ & $\begin{array}{l}58 \\
40 \\
48 \\
15 \\
30\end{array}$ & 4.4 \\
\hline
\end{tabular}

Table II (continued).

\begin{tabular}{|c|c|c|}
\hline \multirow{2}{*}{$\begin{array}{c}\text { Experimental } \\
\text { Quantity }\end{array}$} & \multicolumn{2}{|c|}{$697-1300 \mathrm{MeV}$} \\
\hline & $\begin{array}{l}\text { Number of } \\
\text { Points }\end{array}$ & Percent \\
\hline $\begin{array}{l}A_{\mathrm{oonn}} \\
A_{\mathrm{ookk}} \\
A_{\mathrm{oosk}}\end{array}$ & $\begin{array}{r}393 \\
325 \\
60\end{array}$ & \multirow[t]{2}{*}{18.0} \\
\hline$N_{\text {onkk }}$ & 8 & \\
\hline Total & 4356 & 100.0 \\
\hline $\begin{array}{l}\text { Contributed } \\
\text { Points }\end{array}$ & 4260 & 97.8 \\
\hline Omitted Points & 96 & 2.2 \\
\hline
\end{tabular}

3.3 FitTING PROCEDURE. - All experimental data were fitted according to the standard $\chi^{2}$-method, including the error matrix calculation (see e.g. Ref. 
[51]) with the statistical errors quoted by the authors. The systematic errors were taken into account by introducing a variable normalization factor multiplying each data set. These factors were kept only if their values differed from one by more than their errors. We found that most of the remaining normalization factors are applied to differential cross-sections. Our $\chi^{2}$ sum thus correctly reflects the systematic experimental uncertainties. Experimental points for which the $\chi^{2}$-contribution was larger than 10 were omitted from the analysis. These represent $2.2 \%$ of the data but in about one half of the omitted data $(1 \%)$ the quoted statistical errors were very small, probably underestimated in original references.

Several incompatible sets which exist below $800 \mathrm{MeV}$ were discussed in reference [1]. Above $800 \mathrm{MeV}$ no important discrepancies between different data sets were found.

The phase shifts varied in the present PSA and the number of free coefficients necessary to describe their energy dependences are listed in the bottom row of table III. The influence of higher $n$ terms in equations (1) and (2) on the $\chi^{2}$ value were carefully tested as well as the influence of all possible imaginary parts of phase shifts. It was found necessary to fit the $J=8$ real parts of phase shifts in order to reproduce the spin dependent parameters up to $1.3 \mathrm{GeV}$. The phase shifts with $J_{\max }=6$ are sufficient to fit the data up to $1.1 \mathrm{GeV}$. The imaginary parts of all phase shifts not used in our analysis presented a negligible influence on the $\chi^{2}$ value.

3.4 AmbiguitiEs. - The direct reconstruction of the scattering matrix and conditions for an unique solution of the PSA have been discussed in detail in references [13, 52-59]. We present here a brief summary relevant to this PSA.

A direct reconstruction of the five complex $\mathrm{pp} \Rightarrow \mathrm{pp}$ scattering amplitudes at one energy and one scattering angle $\theta_{\mathrm{CM}}$ requires determining 9 real values from the existing data (one value is arbitrary due to the overall common phase). The set of measured observables allowing the reconstruction of the scattering matrix at one energy and one angle is called «the complete set of observables » $[52,53]$. Since the amplitudes are bilinear functions of the observables, the number of observables for a complete set vary from 9 to 18 depending on the choice of experiments [54-57]. An optimal set would contain at least 11 different observables. The complete set of observables in a large angular region was measured for the first time at SIN at few energies and scattering amplitudes were reconstructed [58, 59].

The expansion of amplitudes as a Legendre polynomial series truncated at a given $L_{\max }$ and the replacement of the remaining terms by OPE are powerful constraints [60]. For fixed energy PSA these constraints decrease not only the required number of experimental points for each observable, but could, in principle decrease even the number of necessary observables. Indeed, statistical criteria often allow one to reject solutions having a small probability and the PSA can be unambiguous even if the number of independent observables is considerably lower than eleven. In connection with the phase shift analysis, Klepikov [61-63] introduced the concept of a « sufficient set of observables » (called also

Table III. - Real parts of pp phase shifts in degrees.

\begin{tabular}{|c|c|c|c|c|c|c|c|c|}
\hline \multirow{2}{*}{$\begin{array}{c}T_{\text {kin }} \\
(\mathrm{MeV})\end{array}$} & & \multicolumn{7}{|c|}{ Real Parts of pp Phase Shifts [deg] } \\
\cline { 2 - 9 } & ${ }^{1} \mathrm{~S}_{0}$ & ${ }^{3} \mathrm{P}_{0}$ & ${ }^{3} \mathrm{P}_{1}$ & ${ }^{3} \mathrm{P}_{2}$ & ${ }^{1} \mathrm{D}_{2}$ & $\varepsilon_{2}$ & ${ }^{3} \mathrm{~F}_{2}$ & ${ }^{3} \mathrm{~F}_{3}$ \\
\hline 700 & -33.98 & -41.48 & -46.50 & 20.85 & 6.69 & -0.05 & -2.83 & -0.66 \\
750 & -37.71 & -42.90 & -45.31 & 20.26 & 4.50 & -1.40 & -3.66 & -4.09 \\
800 & -38.73 & -44.01 & -44.52 & 19.70 & 2.51 & -2.00 & -4.56 & -6.68 \\
850 & -38.01 & -44.84 & -44.09 & 19.19 & 0.71 & -1.93 & -5.55 & -8.48 \\
900 & -36.46 & -45.42 & -44.00 & 18.73 & -0.88 & -1.31 & -6.62 & -9.55 \\
950 & -34.83 & -45.85 & -44.21 & 18.33 & -2.27 & -0.28 & -7.77 & -10.00 \\
1000 & -33.84 & -45.88 & -44.66 & 18.02 & -3.45 & 1.04 & -9.00 & -9.95 \\
1050 & -34.13 & -45.82 & -45.30 & 17.78 & -4.43 & 2.49 & -10.31 & -9.52 \\
1100 & -36.26 & -45.60 & -46.09 & 17.63 & -5.19 & 3.91 & -11.70 & -8.86 \\
1150 & -40.78 & -45.25 & -46.95 & 17.57 & -5.74 & 5.14 & -13.17 & -8.15 \\
1200 & -48.18 & -44.77 & -47.83 & 17.60 & -6.08 & 5.99 & -14.72 & -7.55 \\
1250 & -58.92 & -44.20 & -48.67 & 17.72 & -6.21 & 6.30 & -16.36 & -7.24 \\
1300 & -73.45 & -43.57 & -49.39 & 17.93 & -6.12 & 5.87 & -18.07 & -7.44 \\
\hline Free & 4 & 4 & 4 & 4 & 4 & 4 & 3 & 4 \\
Coef. & & & & & & & & \\
\hline
\end{tabular}


Table III (continued).

\begin{tabular}{|c|c|c|c|c|c|c|c|c|}
\hline \multirow{2}{*}{$T_{\text {kin }}$} & & \multicolumn{2}{|c|}{ Real Parts of pp Phase Shifts [deg] } & \\
\cline { 2 - 9 }$(\mathrm{MeV})$ & ${ }^{3} \mathrm{~F}_{4}$ & ${ }^{1} \mathrm{G}_{4}$ & $\varepsilon_{4}$ & ${ }^{3} \mathrm{H}_{4}$ & ${ }^{3} \mathrm{H}_{5}$ & ${ }^{3} \mathrm{H}_{6}$ & ${ }^{1} \mathrm{I}_{6}$ & $\varepsilon$ \\
\hline 700 & 6.46 & 4.25 & -1.95 & -0.35 & -1.39 & 1.68 & 1.16 & -1.19 \\
750 & 6.51 & 4.03 & -2.06 & -0.43 & -1.40 & 1.69 & 1.13 & -1.24 \\
800 & 6.53 & 3.79 & -2.10 & -0.52 & -1.41 & 1.68 & 1.08 & -1.29 \\
850 & 6.51 & 3.54 & -2.08 & -0.61 & -1.41 & 1.65 & 1.03 & -1.33 \\
900 & 6.45 & 3.28 & -2.00 & -0.70 & -1.40 & 1.61 & 0.99 & -1.37 \\
950 & 6.37 & 3.03 & -1.84 & -0.81 & -1.30 & 1.55 & 0.93 & -1.41 \\
1000 & 6.26 & 2.77 & -1.62 & -0.91 & -1.38 & 1.48 & 0.87 & -1.45 \\
1050 & 6.12 & 2.50 & -1.32 & -1.02 & -1.36 & 1.41 & 0.81 & -1.49 \\
1100 & 5.96 & 2.24 & -0.94 & -1.13 & -1.33 & 1.32 & 0.75 & -1.52 \\
1150 & 5.77 & 1.98 & -0.49 & -1.25 & -1.30 & 1.21 & 0.68 & -1.55 \\
1200 & 5.57 & 1.71 & 0.05 & -1.37 & -1.27 & 1.10 & 0.62 & -1.58 \\
1250 & 5.34 & 1.45 & 0.67 & -1.49 & -1.23 & 0.98 & 0.55 & -1.61 \\
1300 & 5.10 & 1.19 & 1.37 & -1.62 & -1.19 & 0.85 & 0.48 & -1.64 \\
\hline Free & 2 & 2 & 3 & 2 & 2 & 2 & 2 & 1 \\
Coef. & & & & & & & & \\
\hline
\end{tabular}

Table III (continued).

\begin{tabular}{|c|c|c|c|c|c|c|}
\hline & \multicolumn{7}{|c|}{ Real Parts of pp Phase Shifts [deg] } \\
\cline { 2 - 7 }$(\mathrm{MeV})$ & ${ }^{3} \mathrm{~J}_{\mathbf{6}}$ & ${ }^{3} \mathrm{~J}_{\mathbf{7}}$ & ${ }^{3} \mathrm{~J}_{\mathbf{8}}$ & ${ }^{1} \mathrm{~K}_{\mathbf{8}}$ & $\boldsymbol{\varepsilon}_{\mathbf{8}}$ & ${ }^{3} \mathrm{~L}_{\mathbf{8}}$ \\
\hline 700 & 0.20 & -1.14 & 0.56 & 0.53 & -0.30 & 0.09 \\
750 & 0.13 & -1.31 & 0.61 & 0.39 & -0.32 & 0.11 \\
800 & 0.04 & -1.49 & 0.65 & 0.23 & -0.34 & 0.14 \\
850 & -0.05 & -1.67 & 0.69 & 0.06 & -0.35 & 0.16 \\
900 & -0.15 & -1.86 & 0.73 & -0.12 & -0.37 & 0.19 \\
950 & -0.27 & -2.05 & 0.77 & -0.31 & -0.38 & 0.22 \\
1000 & -0.39 & -2.25 & 0.81 & -0.50 & -0.39 & 0.25 \\
1050 & -0.52 & -2.46 & 0.85 & -0.70 & -0.41 & 0.28 \\
1100 & -0.66 & -2.67 & 0.89 & -0.91 & -0.42 & 0.31 \\
1150 & -0.80 & -2.88 & 0.92 & -1.12 & -0.43 & 0.35 \\
1200 & -0.96 & -3.10 & 0.96 & -1.34 & -0.44 & 0.39 \\
1250 & -1.12 & -3.32 & 0.99 & -1.56 & -0.45 & 0.42 \\
1300 & -1.29 & -3.55 & 1.02 & -1.78 & -0.46 & 0.46 \\
\hline Free & 2 & 2 & 1 & 2 & 1 & 2 \\
Coef. & & & & & & \\
\hline
\end{tabular}

« necessary experiments ») allowing to obtain a unique (or more precisely two-valued above the pion production threshold) PSA solution. Klepikov has determined the necessary number of experimental points as well as the number of observables which must be measured. His method can minimize the data taking time at a given energy but necessitates an interactive procedure between measurements and the PSA [64]. Here we restrict ourself to the case when all measured observables are determined with a good precision in a large angular range. In fact, a precise measured angular dependence of one observable at one energy must be fitted by a polynomial with degree $L_{\max }$ and, consequently, allows one to determine about $L_{\max }$ free parameters. The total cross sections $\left(\sigma_{\text {tot }}, \Delta \sigma_{T}\right.$ and $\left.\Delta \sigma_{L}\right)$ determine one extra free parameter. For $L_{\max }$ equal 8 five independent experiments can determine about 40 free parameters at one energy (we use 22 real parts and 8 imaginary parts of phase shifts). Of course, our 
sufficient set of observables does not assure a unique solution of the PSA.

The number of free parameters for an energy dependent PSA increases by a factor two or three with respect to an energy fixed PSA. On the other hand the number of parameters that can be to determined increases by the same factor (we use 73 free parameters for the present PSA). Moreover, phase shift energy dependence provides additional powerful constraints. For example the continuity of phase shifts within an energy interval automatically decreases the possible multiplicity of solutions.

Concerning the present PSA we know that the solution is unambiguous at least at two energies namely 800 and $1000 \mathrm{MeV}$. In the vicinity of $800 \mathrm{MeV}$ the number of independent observables corresponds to conditions close to a complete set of experiments in a large angular range. At $\sim 1 \mathrm{GeV}$ there exist 10 to 11 independent observables in the angular range $40^{\circ} \leq \theta_{\mathrm{CM}} \leq 90^{\circ}$ but some of these have relatively large experimental errors. From 800 to $970 \mathrm{MeV}$ there exist eight independent observables and above $1.04 \mathrm{GeV}$ their number is reduced to five but covering almost the entire angular range. Imaginary parts of the amplitudes at $\theta_{\mathrm{CM}}=0^{\circ}$ are well determined by existing measurements of $\sigma_{\text {tot }}$, $\Delta \sigma_{T}$ and $\Delta \sigma_{L}$. The Gatchina $\mathrm{d} \sigma / \mathrm{d} \Omega$ data at small angles $[22,23]$ determine the real parts of amplitudes at $\theta=0^{\circ}$ below $1 \mathrm{GeV}$. Energy dependences of the phase shifts are strongly constrained by the $\mathrm{d} \sigma / \mathrm{d} \Omega$ points at $\theta_{\mathrm{CM}} \sim 90^{\circ}$ measured in a jet-target experiment at Saturne II [24] up to $1.2 \mathrm{GeV}$. The results of $A_{\text {oono }}$ measured in the angular range $35^{\circ} \leq \theta_{\mathrm{CM}} \leq 88^{\circ}$ in small energy steps [30] give another excellent constraints for phase shift energy dependence below $1 \mathrm{GeV}$. The extension of the PSA up to $1.3 \mathrm{GeV}$ was possible only by adding the recent analysing power $\left(A_{\text {oono }}\right)$ and spin correlation ( $A_{\text {oonn }}$ and $A_{\text {ookk }}$ ) data [31-34, 45, 47, 48] measured at Saturne II with a good precision in a large angular region $\left(20^{\circ} \leq \theta_{\mathrm{CM}} \leq 100^{\circ}\right)$.

Some of the phase shift energy dependences, mainly above $1 \mathrm{GeV}$, may change when all results from Saturne II are available.

\section{Results and discussion.}

Phase shift values found in the present PSA are given in tables III and IV. Both real and imaginary phase shifts are given in degrees. The $\chi^{2}$ value of the fit per degree of freedom is 1.41 .

The starting values for the analysis were taken from our fixed energy solution at $1 \mathrm{GeV}$ [1]. The thresholds of the imaginary parts of S, P, D, F, G and $\mathrm{H}$ waves were studied. The thresholds for $\operatorname{Im}{ }^{1} \mathrm{~S}_{0}, \operatorname{Im}{ }^{3} \mathrm{P}_{1}$ and $\operatorname{Im}{ }^{3} \mathrm{H}_{5}$ are found to be 750,920 and $900 \mathrm{MeV}$, respectively, the threshold for other imaginary parts were taken from reference [1] and fixed here. Note, that the contribution of the Im ${ }^{3} \mathrm{P}_{0}$, found to be negligibly small in our analysis, is hard to separate from that of the other P-wave imaginary parts.

The energy dependences of the S, P, D, F, G, H, $\mathrm{I}, \mathrm{J}, \mathrm{K}$ and $\mathrm{L}$ phase shifts and mixing parameters are shown in figures 1-14 together with our previous results below $800 \mathrm{MeV}$ (full lines) and the starting points at $1 \mathrm{GeV}$ (black dots). One can see that

Table IV. - Imaginary parts of pp phase shifts in degrees.

\begin{tabular}{|c|c|c|c|c|c|c|c|c|}
\hline \multirow{2}{*}{$T_{\text {kin }}(\mathrm{MeV})$} & \multicolumn{7}{|c|}{ Imaginary Parts of pp Phase shifts [deg] } \\
\cline { 2 - 9 } & $\operatorname{Im}^{1} \mathrm{~S}_{0}$ & $\operatorname{Im}^{3} \mathrm{P}_{1}$ & $\operatorname{Im}^{3} \mathrm{P}_{2}$ & $\operatorname{Im}{ }^{1} \mathrm{D}_{2}$ & $\operatorname{Im}^{3} \mathrm{~F}_{2}$ & $\operatorname{Im}^{3} \mathrm{~F}_{3}$ & $\operatorname{Im}^{1} \mathrm{G}_{4}$ & $\operatorname{Im}^{3} \mathrm{H}_{5}$ \\
\hline 700 & & & 10.03 & 12.09 & 1.44 & 10.33 & 0.29 & \\
750 & & & 12.17 & 14.44 & 2.41 & 13.85 & 0.50 & \\
800 & 0.04 & & 14.26 & 16.74 & 3.70 & 17.47 & 0.81 & \\
850 & 0.20 & & 16.26 & 18.91 & 5.32 & 20.92 & 1.22 & 0.00 \\
900 & 0.55 & & 18.16 & 20.89 & 7.27 & 23.96 & 1.73 & 0.00 \\
950 & 1.14 & 0.01 & 19.96 & 22.58 & 9.50 & 26.41 & 2.33 & 0.00 \\
1000 & 1.99 & 0.12 & 21.63 & 23.93 & 11.96 & 28.20 & 3.01 & 0.00 \\
1050 & 3.13 & 0.39 & 23.19 & 24.87 & 14.56 & 29.42 & 3.74 & 0.00 \\
1100 & 4.61 & 0.87 & 24.63 & 25.34 & 17.19 & 30.37 & 4.78 & 0.02 \\
1150 & 6.43 & 1.61 & 25.96 & 25.30 & 19.68 & 31.62 & 5.16 & 0.06 \\
1200 & 8.63 & 2.64 & 27.20 & 24.70 & 21.86 & 34.09 & 5.73 & 0.17 \\
1250 & 11.24 & 3.98 & 28.35 & 23.51 & 23.50 & 39.12 & 6.09 & 0.40 \\
1300 & 14.26 & 5.66 & 29.43 & 21.72 & 24.34 & 48.48 & 6.15 & 0.88 \\
\hline Free & & & & & & & & \\
Coef. & 1 & 1 & 3 & 3 & 2 & 3 & 3 & 1 \\
\hline
\end{tabular}


almost all phase shifts connect smoothly with our solution at lower energies. The apparent disconnection of the $\mathrm{Im}^{1} \mathrm{G}_{4}$ is probably due to the fact that in the lower energy interval $(500-800 \mathrm{MeV})$ we have not allowed ${ }^{1} \mathrm{~S}_{0}$ to be imaginary. The " corridor of errors ", shown only for the fixed energy analysis at $1 \mathrm{GeV}$, was calculated as the square root of the corresponding diagonal element of the error matrix. It is much narrower than the error corresponding to the « confidence level $1 \sigma$ » due to the large contribution of the non-diagonal elements in the error matrix, as was discussed in reference [1].

Our results in figures 1-13 are compared with the energy dependent PSA of Arndt et al. [3] (dotdashed line) and with the results of representative fixed-energy phase shift analyses above $800 \mathrm{MeV}$ (triangles [5], open circles [6], diamonds [7]). Below $800 \mathrm{MeV}$ a comparison with the locally energydependent PSA of Dubois et al. [8] is also shown (black squares). The imaginary parts of phase shifts are also compared with the Paris potential prediction [10] (dashed line). All phase shifts have been converted into our representation; this transformation mainly changes the imaginary parts. Only the phase shifts left free are shown in the figures. The comparison of the results below $800 \mathrm{MeV}$ was discussed in reference [1]. The energy dependences above $800 \mathrm{MeV}$ show a general agreement with

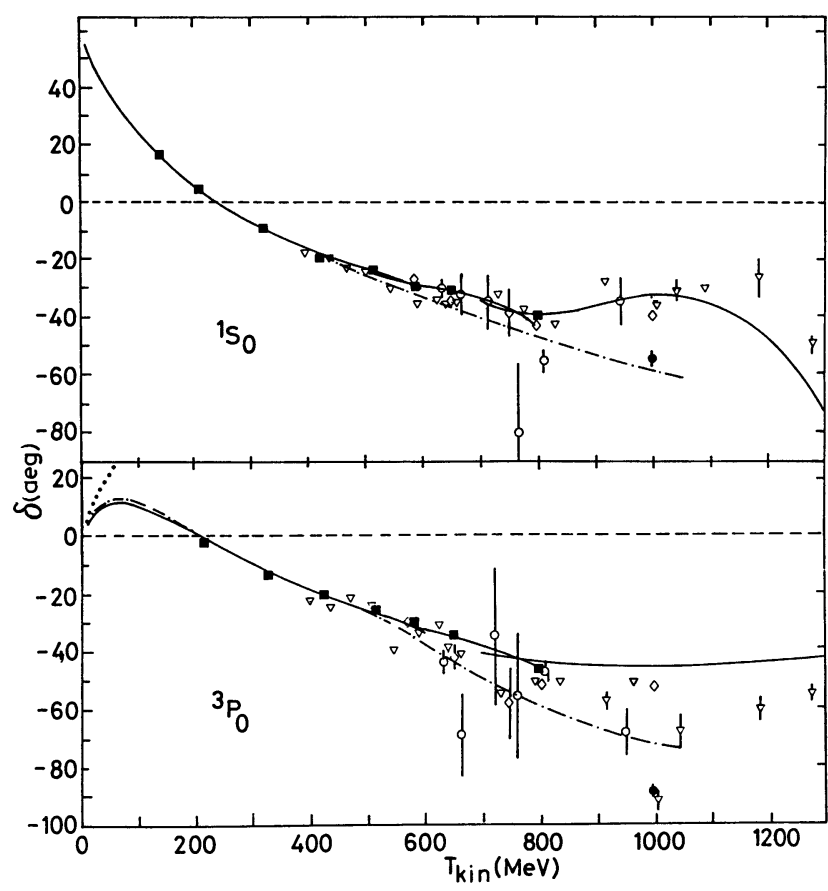

Fig. 1. - Energy dependences of ${ }^{1} S_{0}$ and ${ }^{3} P_{0}$ phase shifts. Present analysis and PSA of reference [1] ; • Previous fixed energy solution at $1 \mathrm{GeV} ;-.+-$. Analysis of reference [3]; $\nabla$ Analysis of reference [5] ; O Analysis of reference [6]; $\diamond$ Analysis of reference [7] ; 1 Analysis of reference $[8] ; \ldots .$. OPE and electromagnetic correction.

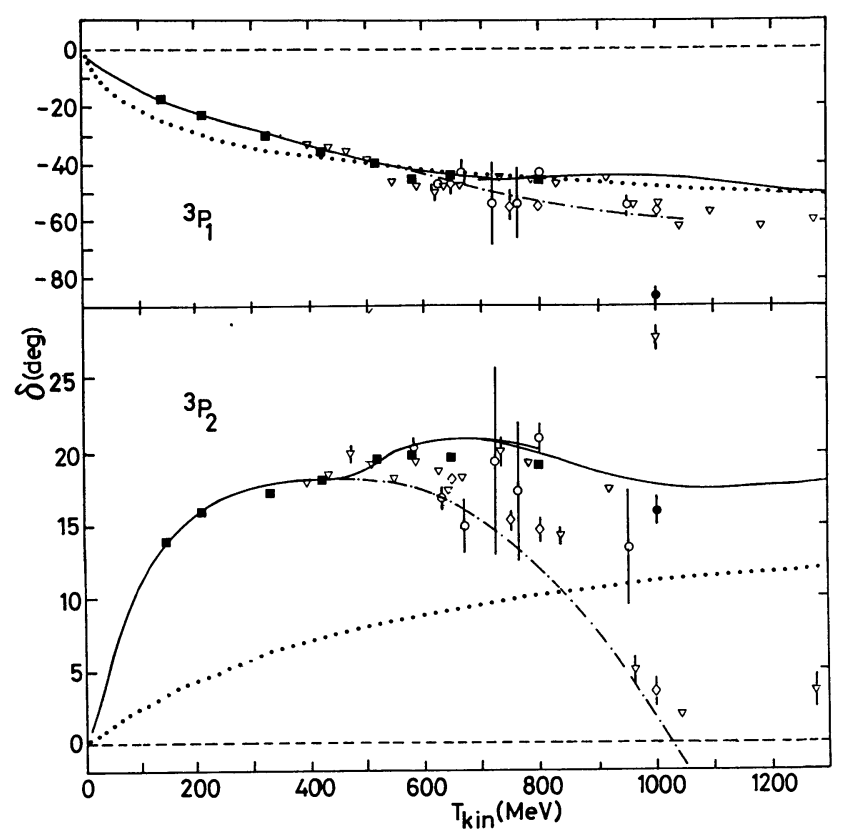

Fig. 2. - Energy dependence of ${ }^{3} \mathrm{P}_{1}$ and ${ }^{3} \mathrm{P}_{2}$ phase shifts. Symbols are defined in figure 1.

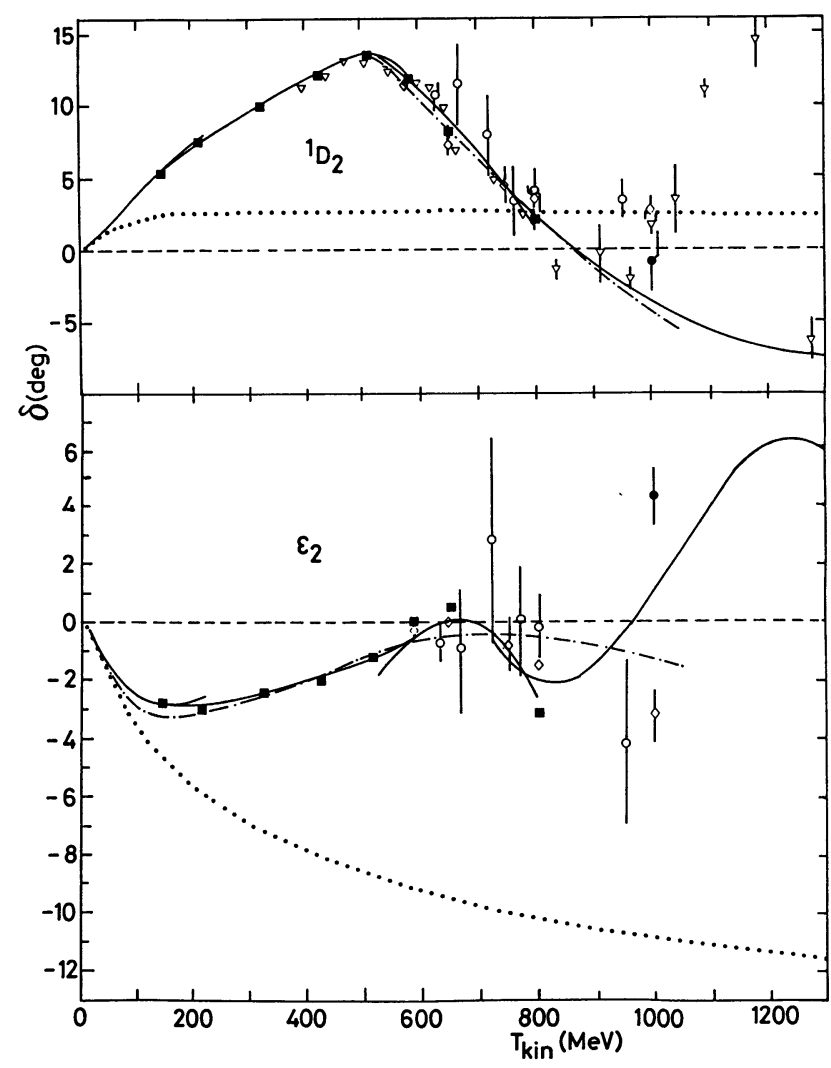

Fig. 3. - Energy dependence of the phase shift ${ }^{1} D_{2}$. and of the mixing parameter $\varepsilon_{2}$. Symbols are defined in figure 1 . 




Fig. 4. - Energy dependence of ${ }^{3} \mathrm{~F}_{2},{ }^{3} \mathrm{~F}_{3}$ and ${ }^{3} \mathrm{~F}_{4}$. Symbols are defined in figure 1.



Fig. 5. - Energy dependence of the phase shift ${ }^{1} \mathrm{G}_{4}$ and of the mixing parameter $\varepsilon_{4}$. Symbols are defined in figure 1 .

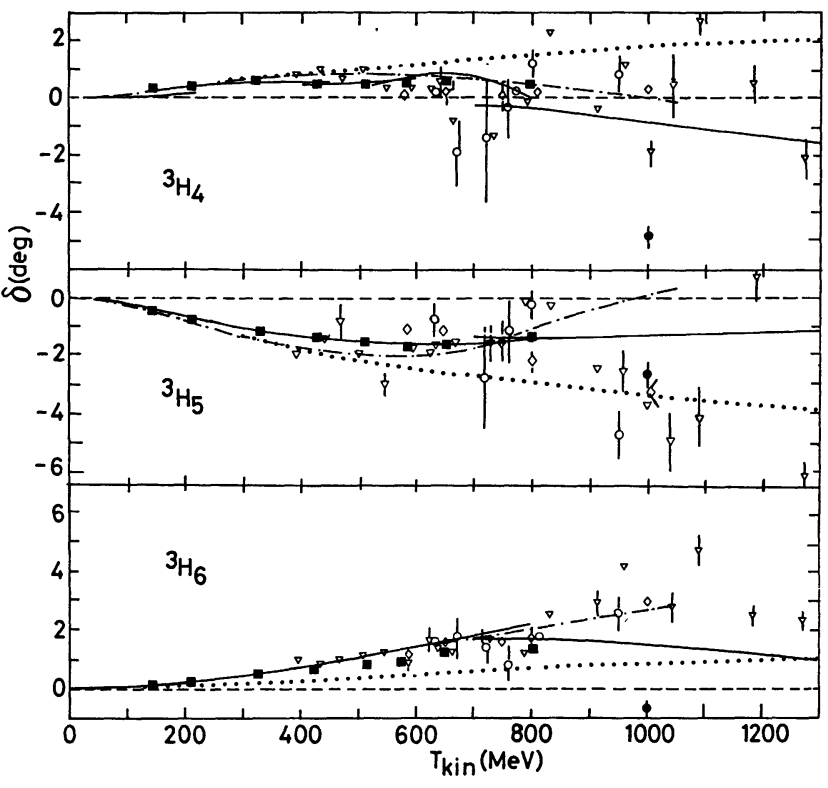

Fig. 6. - Energy dependence of ${ }^{3} \mathrm{H}_{4},{ }^{3} \mathrm{H}_{5}$ and ${ }^{3} \mathrm{H}_{6}$. Symbols are defined in figure 1.

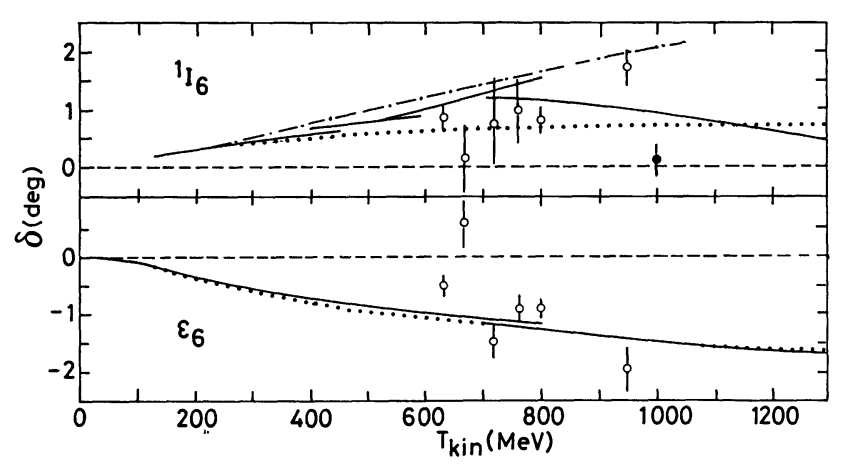

Fig. 7. - Energy dependences of the phase shift ${ }^{1} I_{6}$ and of the mixing parameter $\varepsilon_{6}$. Symbols are defined in figure 1 .

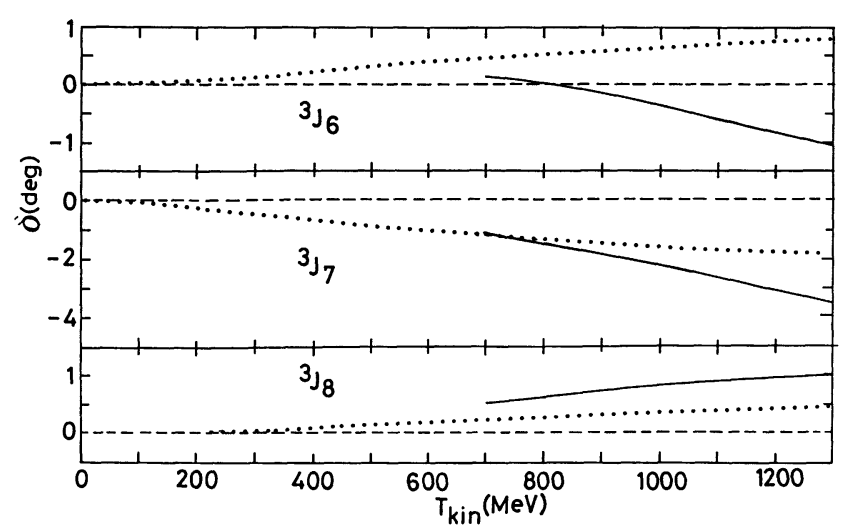

Fig. 8. - Energy dependence of the phase shifts ${ }^{3} \mathrm{~J}_{6},{ }^{3} \mathrm{~J}_{7}$ and ${ }^{3} \mathrm{~J}_{8}$. Symbols are defined in figure 1 . 


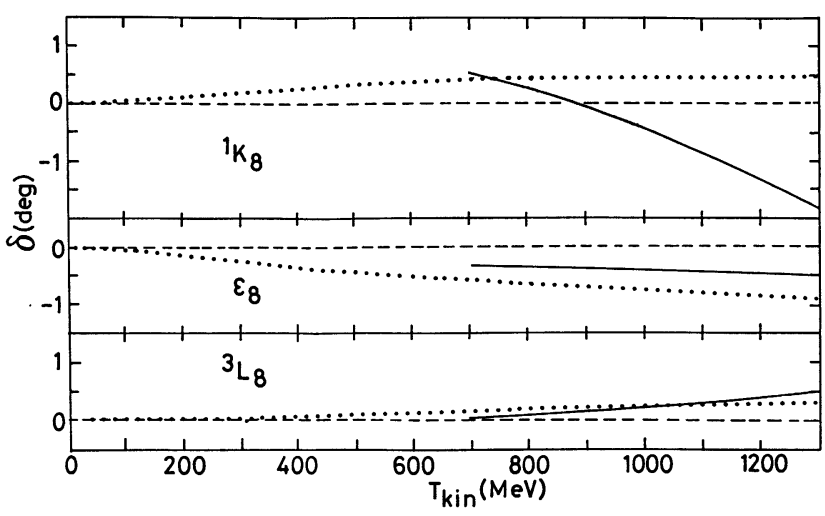

Fig. 9. - Energy dependence of ${ }^{1} K_{8}, \varepsilon_{8}$ and ${ }^{3} L_{8}$. Symbols are defined in figure 1.

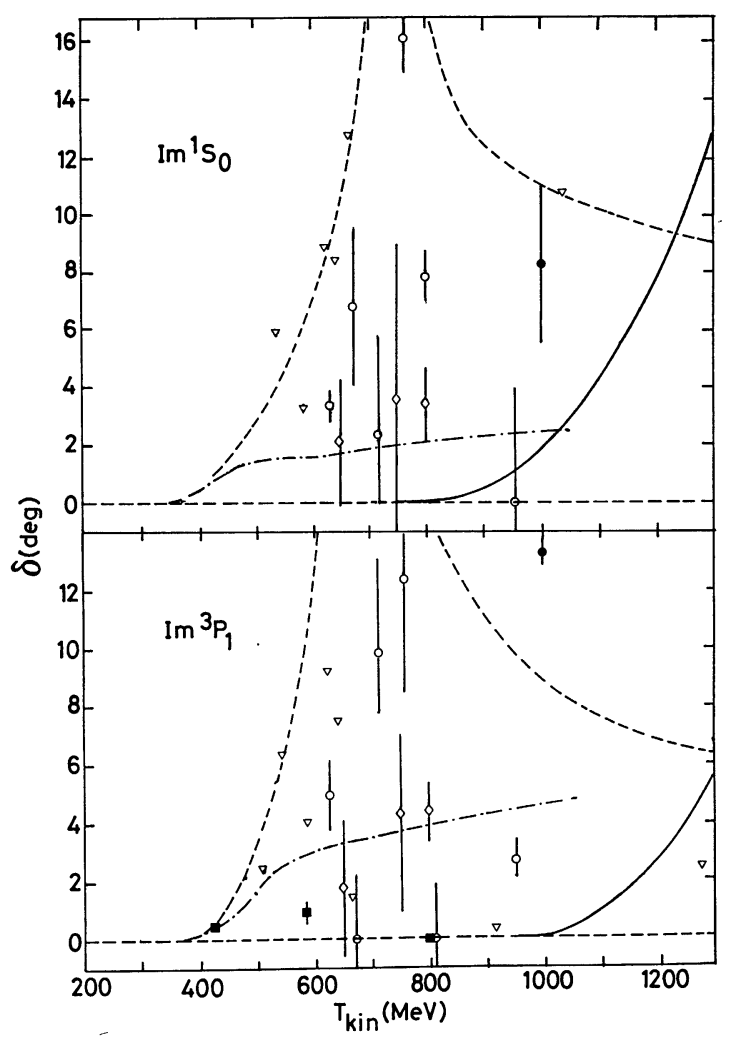

Fig. 10. - Energy dependence of the imaginary parts of the phase shifts ${ }^{1} \mathrm{~S}_{0}$ and ${ }^{3} \mathrm{P}_{1}$. The dashed line is prediction from the Paris potential [10]. Other symbols have been defined in figure 1.

Fig. 12. - Energy dependence of the imaginary parts of ${ }^{3} \mathrm{~F}_{2}$, and ${ }^{3} \mathrm{~F}_{3}$ phase shifts. The symbols are as in figures 1 and 10 .

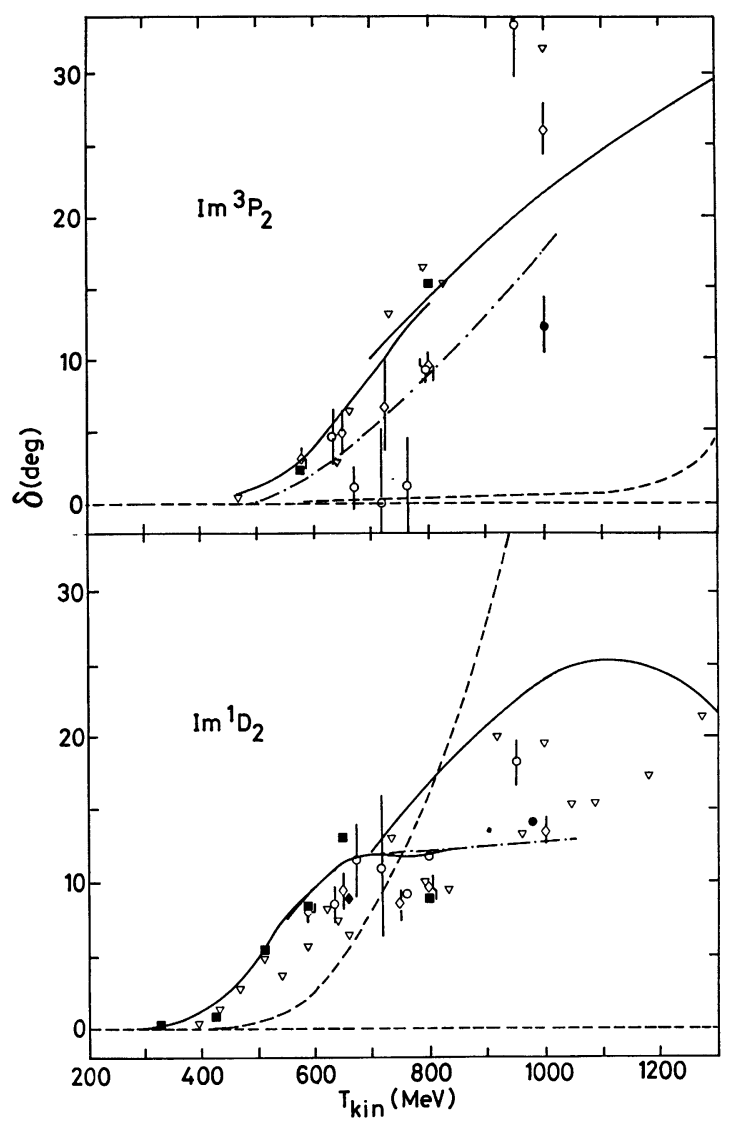

Fig. 11. - Energy dependence of the imaginary parts of ${ }^{3} P_{2}$ and ${ }^{1} D_{2}$ phase shifts. Symbols are defined in figures 1 and 10 .

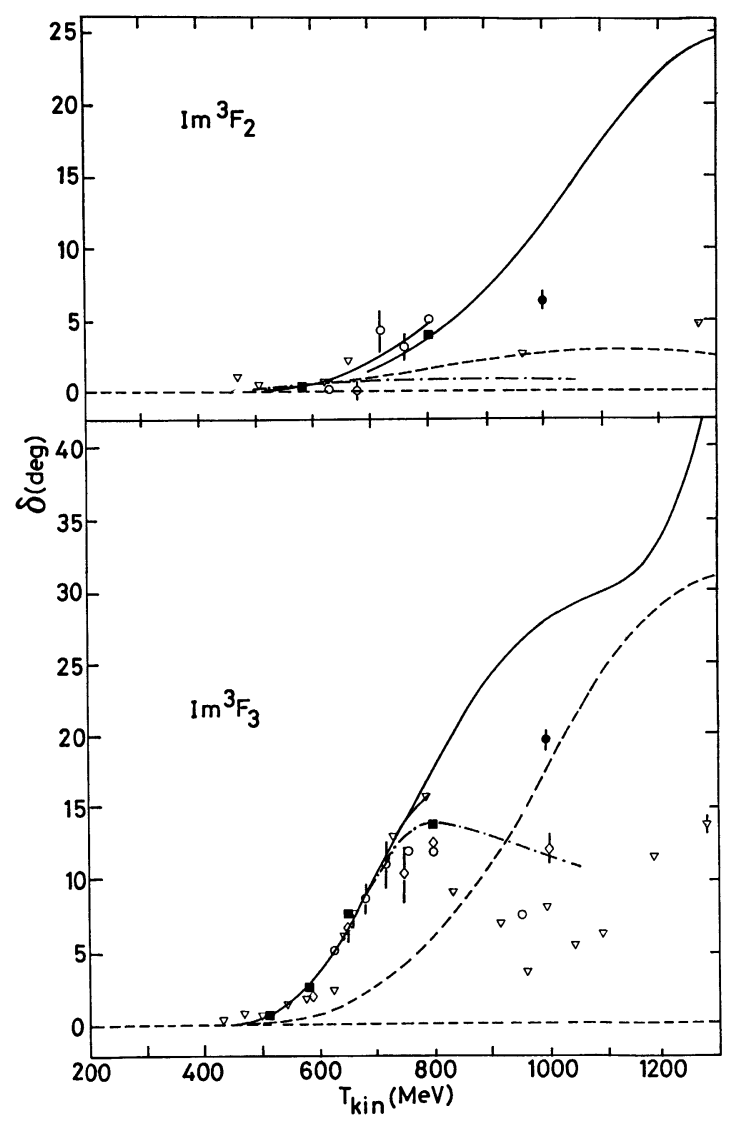




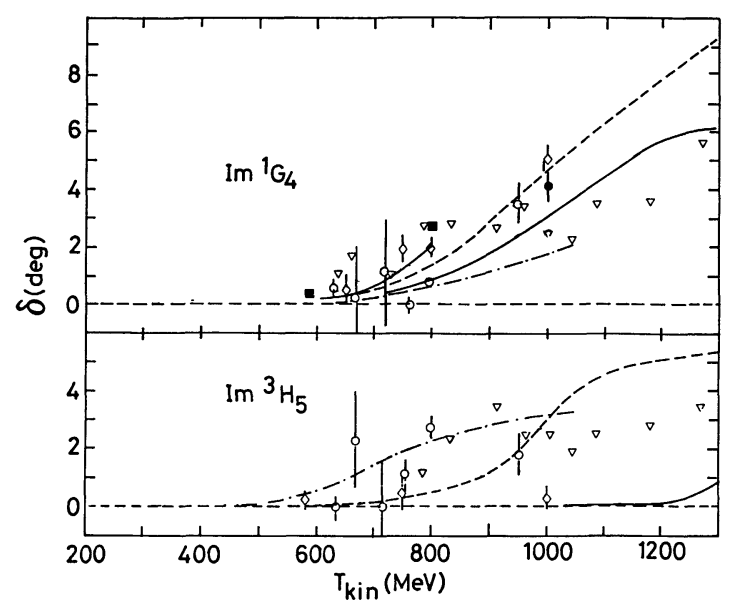

Fig. 13. - Energy dependence of the imaginary parts of ${ }^{1} G_{4}$ and ${ }^{3} H_{5}$ phase shifts.

results of Arndt et al. [3] only for the real parts of ${ }^{3} \mathrm{P}_{1},{ }^{1} \mathrm{D}_{2},{ }^{3} \mathrm{~F}_{2},{ }^{3} \mathrm{~F}_{4},{ }^{3} \mathrm{H}_{4},{ }^{3} \mathrm{H}_{5}$ and ${ }^{3} \mathrm{H}_{6}$ phase shifts and for $\operatorname{Im}{ }^{3} \mathrm{P}_{2}$ and $\operatorname{Im}{ }^{1} \mathrm{G}_{4}$. All other phase shifts and mixing parameters are in strong disagreement. The results of their very recent version [4] differ only little from reference [3]. A most important disagreement can be seen in figure 2 for the $\operatorname{Re}^{3} \mathrm{P}_{2}$ phase shift from $400 \mathrm{MeV}$ on. The present analysis confirms the behaviour observed in reference [1].

This analysis, as well as that of reference [1] below $800 \mathrm{MeV}$ is in good agreement with the results of reference [8]. It is hard to compare our results with those of other analyses at fixed energy above $800 \mathrm{MeV}$, since fixed-energy PSA results are very dispersed. For the $\operatorname{Re}^{1} \mathrm{~S}_{0}$ phase shift there is very good agreement between the present PSA and the results of references [5,7]. For the $\operatorname{Re}^{3} \mathrm{P}_{0}$ and $\operatorname{Re}^{3} \mathrm{P}_{1}$ the fixed energy PSA results are between the present solution and that of reference [3]. We found the $\operatorname{Re}^{3} \mathrm{P}_{1}$ to be very close to the OPE contribution. The energy dependence of $\operatorname{Re}^{3} \mathrm{~F}_{3}$ agree with the results from references $[5,6]$. The imaginary parts differ considerably between different analyses for the ${ }^{1} \mathrm{P}_{0},{ }^{3} \mathrm{P}_{1},{ }^{1} \mathrm{D}_{2},{ }^{3} \mathrm{~F}_{2}$ and ${ }^{3} \mathrm{~F}_{3}$ phase shifts. The solution, given by the present analysis will probably change above $1 \mathrm{GeV}$, but below this energy only small changes should be expected. Finally, we have compared our results for imaginary parts of phase shifts with the Paris potential group latest predictions [10], calculated from a dispersion relation approach [9]. The global energy trend for the ${ }^{1} D_{2},{ }^{3} F_{3}$ and ${ }^{1} \mathrm{G}_{4}$ phase shifts is consistent with ours (see Figs. 11 to 13). A disagreement for $S$ and $P$ phase shifts is not surprizing, since the authors of references $[9,10]$ claim reasonable predictions starting from $J=3$ on. Considering all their imaginary phase shifts, their total inelastic cross section reproduces the energy dependence of the data.
Our earlier single energy solution at $1 \mathrm{GeV}$ [1] differs significantly from the present energy-dependent solution. In the previous analysis, in order to avoid energy dependent developpement of phase shifts, data were considered only in a narrow energy range $(0.97-1.04 \mathrm{GeV})$. This provide us with an uncomplet set of observables between $45^{\circ} \mathrm{CM}$ and $90^{\circ} \mathrm{CM}$ with relative large experimental errors.

No new data have appeared in this energy range, but a significant amount $(~ \sim 210$ data points equivalent to $1 / 3$ of all data used at $1 \mathrm{GeV} »)$ becomes available mainly from KEK, Saturne II and Gatchina in the interval $\pm 100 \mathrm{MeV}$ around $1 \mathrm{GeV}$ (see Tab. I). Moreover, these new data cover the smallangle region $\left(\geq 23^{\circ} \mathrm{CM}\right)$. Under these circonstances it is not surprizing that the solutions differ, since the energy dependence represent a powerful constraint as discussed in section 3.4.

The Argand diagrams shown in figures $14 \mathrm{a}-\mathrm{h}$, also connect smoothly with our previous results. The Argand diagrams for ${ }^{3} \mathrm{P}_{2},{ }^{1} \mathrm{D}_{2},{ }^{1} \mathrm{G}_{4}$ and ${ }^{3} \mathrm{H}_{5}$ show an
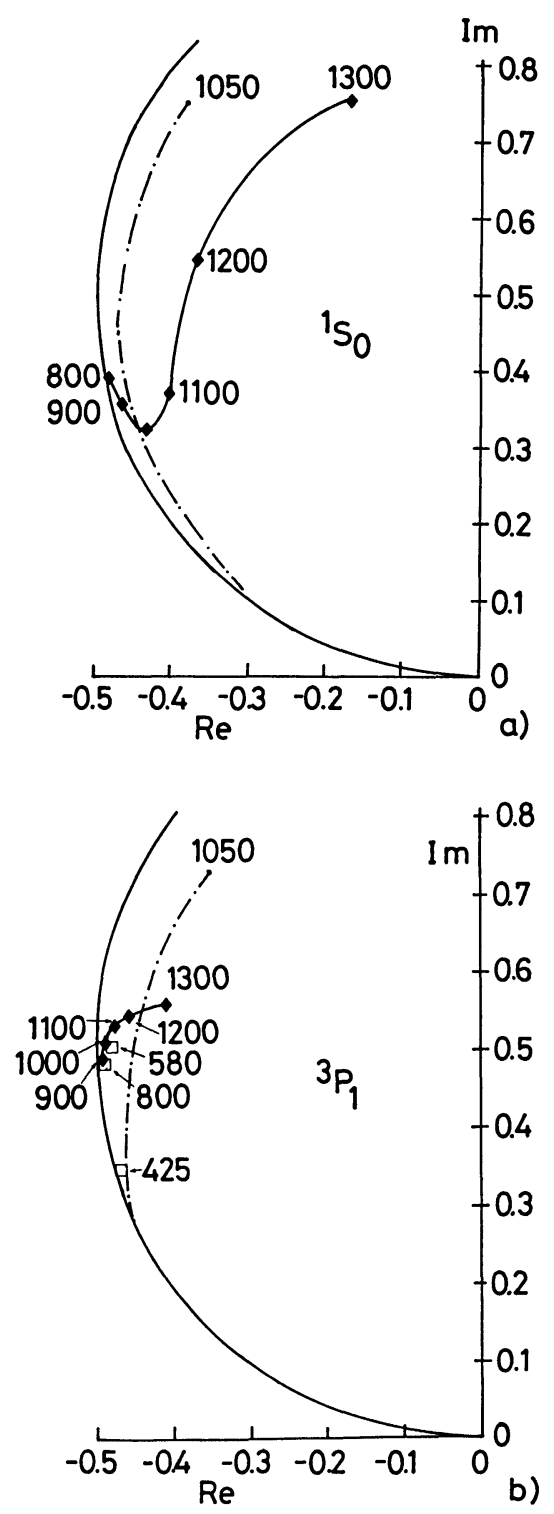


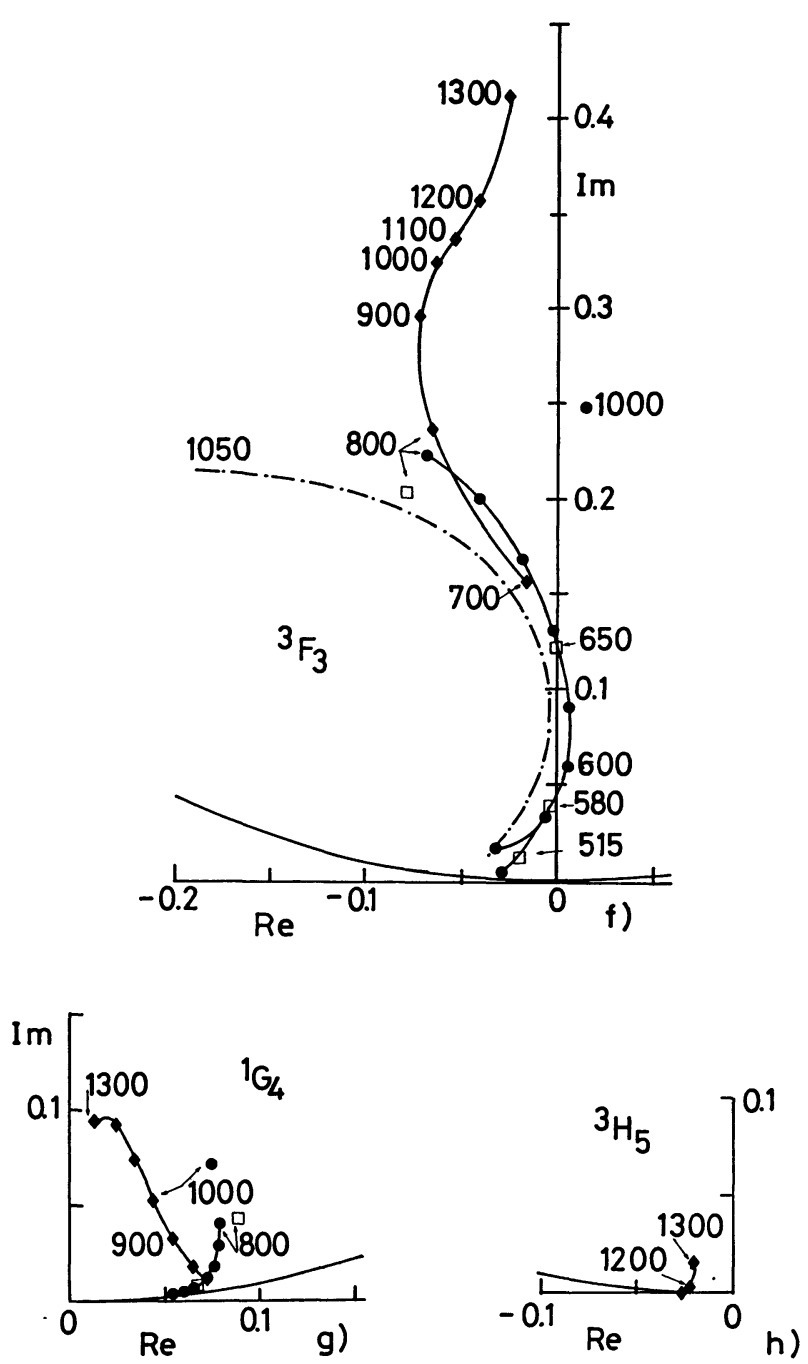

Fig. 14a-h. - Argand diagrams for $\longrightarrow \longrightarrow$ Previous analysis every $40 \mathrm{MeV}$ [1]; • Previous fixed-energy solution at $1 \mathrm{GeV}[1] ; \multimap$ Present analysis every $100 \mathrm{MeV} ;-.-\ldots$. Analysis of reference [3] ; $\square$ Analysis of reference [8] at 325, 425, 515, 580, 650 and $800 \mathrm{MeV}$. For each energy only the phase shifts with model-independent imaginary parts are represented.

anticlockwise behaviour in the entire energy range. The change of the initial anticlockwise behaviour of the ${ }^{3} F_{3}$ phase shift into a slow clockwise movement above $800 \mathrm{MeV}$ bring into question the existence of a resonance at the total energy of $2.22 \mathrm{GeV}$, as claimed by many authors. The shape of the Argand diagram for ${ }^{3} \mathrm{P}_{2}$ (Fig. 14c) may be consistent with a possible resonance structure in one of the $P$ waves, suggested by Lomon [65]. The structure in $\operatorname{Re}^{3} \mathrm{P}_{2}$ above $400 \mathrm{MeV}$ (Fig. 2) observed in reference [1] and confirmed here supports this suggestion. The singlet-spin state partial waves ${ }^{1} \mathrm{D}_{2}$ and ${ }^{1} \mathrm{G}_{4}$ show interesting behaviour between 1.1 and $1.3 \mathrm{GeV}$. To establish a possible resonance-like structure in the ${ }^{1} \mathrm{G}_{4}$ wave, which may occur at $\sim 1.3 \mathrm{GeV}$, an extension of the PSA to higher energies is necessary. 
Our results are compared with those of references [3] (dot-dashed line) and [8] (open squares).

The energy dependences of the real to imaginary part ratio of the spin independent forward amplitude $[\operatorname{Re}(a+b) / \operatorname{Im}(a+b)]$ and of the total cross section differences $\sigma_{1 \text { tot }}=-\Delta \sigma_{T} / 2$ and $-\Delta \sigma_{L}$ are shown in figures 15 to 17 (together with all existing data). We have not used dispersion relation predictions [66] as input into our analysis. Nevertheless, these are in excellent agreement with our solution as can be seen in figure 15. The $\sigma_{1 \text { tot }}$ (Fig. 16) does not



Fig. 15. - Energy dependence of $\operatorname{Re}(a+b) / \operatorname{Im}(a+b)$ at $\theta=0$. Dispersion relation prediction [64] is shown as dotted line.

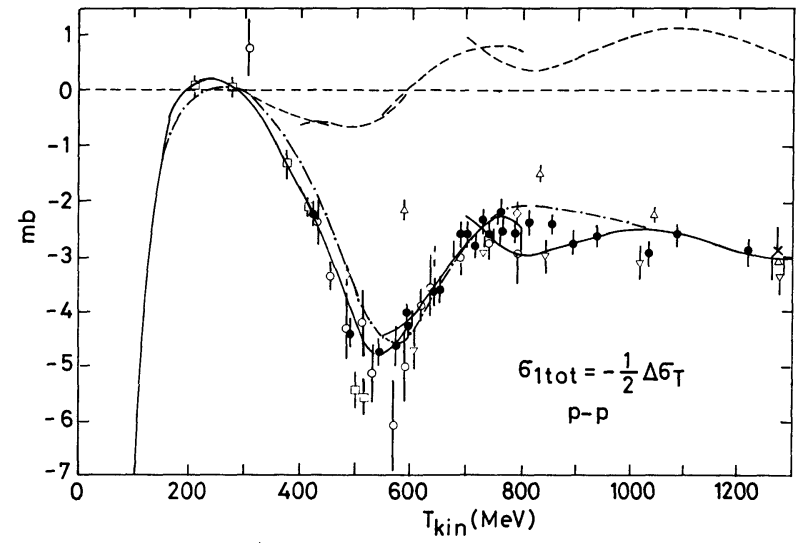

Fig. 16. - Energy dependence of $\sigma_{1 \text { tot }}(\mathrm{pp})=$ $-\Delta \sigma_{T}(\mathrm{pp}) / 2$. - this PSA and reference [1];-.- - reference [3] ; ------ $\sigma_{1 \text { tot }}(\mathrm{el})$, this analysis and reference [1] ; $\bullet$ Saturne II, reference [17] ; $\square$ TRIUMF, reference [67] ; $\diamond$ LAMPF, reference [18] ; O RiceLAMPF, reference [19]; $\nabla$ Rice-ZGS, reference [19] ; $\triangle$ ZGS-ANL, reference 78/B-248/ in [2] ; $\times$ ZGS-ANL, reference $75 / \mathrm{D}-80 /$ in [2].

connect smoothly with the energy dependence established in reference [1] even if the experimental points are fairly well fitted. There is a lack of constraints below $700 \mathrm{MeV}$ where the absolute value of $\sigma_{1 \text { tot }}$ increases rapidly. Anyway the difference in the overlapping region is $\leq 0.5 \mathrm{mb}$ which is comparable to the experimental errors. The $-\Delta \sigma_{L}$ total cross section difference (Fig. 17) connects smoothly with our previous results in the overlapping region. A lack of data around $1.2 \mathrm{GeV}$ allows the decrease in $-\Delta \sigma_{L}$ values. Our predictions for $\sigma_{1 \text { tot }}$ and $\Delta \sigma_{L}$ are compared with the predictions of reference [3]. In figures. 16 and 17 are also plotted predictions for the elastic parts of $\sigma_{1 \text { tot }}$ and $-\Delta \sigma_{L}$ as dashed line. These results confirm that the elastic part of $\sigma_{1 \text { tot }}$ is small and that for $\Delta \sigma_{L}(\mathrm{el})$ is large.

Our analysis fits well the observed crossing of zero analysing power $A_{\mathrm{oono}}$ at $\theta_{\mathrm{CM}}=90^{\circ}$ from negative to positive sign above $1.15 \mathrm{GeV}$. This behaviour, definitely established at Saturne II $[32,45]$, can be seen in figure 18 where the angular dependence $A_{\text {oono }}=f\left(\theta_{\mathrm{CM}}\right)$ is plotted for three energies.

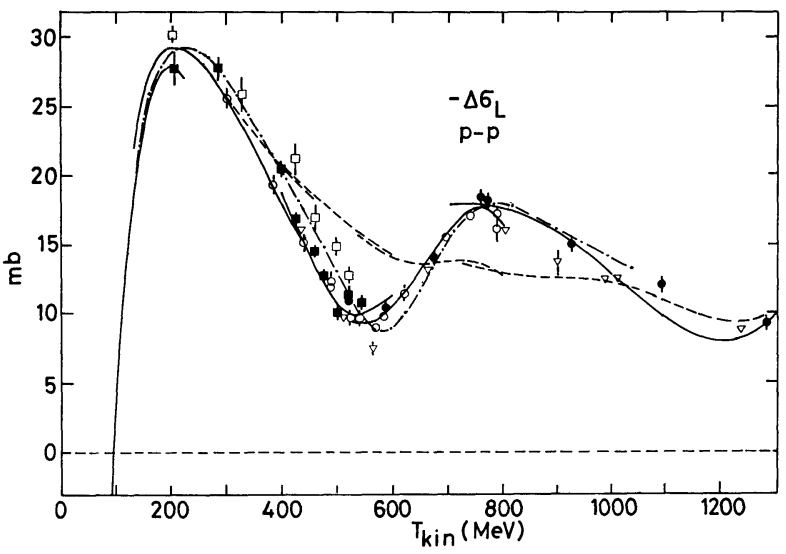

Fig. 17. - Energy dependence of $-\Delta \sigma_{L}(\mathrm{pp})$. - this PSA and reference [1] ; -.-. reference [3] ; -.-.--$-\Delta \sigma_{L}(\mathrm{el})$, this PSA and reference [1]; $\boldsymbol{\square}$ SIN, reference [68] ; • Saturne II, reference [21] ; $\square$.TRIUMF, reference [67] ; O LAMPF, reference [20]; $\nabla$ ZGS-ANL, reference $78 / \mathrm{A}-164 /$ in [2].

In figure 19 are shown the energy dependences of the spin correlation parameters $A_{\text {oonn }}, A_{\text {ookk }}$ and $A_{\text {ooss }}$ at $\theta_{\mathrm{CM}}=90^{\circ}$ as calculated from this PSA and from reference [1]. Also are plotted all data points above $700 \mathrm{MeV}$ measured close to $90^{\circ} \mathrm{CM}$. A local maximum at $\sim 1.15 \mathrm{GeV}$ in the $A_{\text {oonn }}$ (as well as in $\left.A_{\text {ooss }}\right)$ energy dependence may be due to a lack of experimental data and needs confirmation. On the other hand the decrease observed at $1.3 \mathrm{GeV}$ for all three parameters, is confirmed by existing data above this energy $[45,48]$. This supports a possible singlet spin state resonance in ${ }^{1} \mathrm{G}_{4}$ partial wave around $1.3 \mathrm{GeV}$.

\section{Conclusions.}

The present PSA fits well all existing experimental data points including the new Saclay results. The 


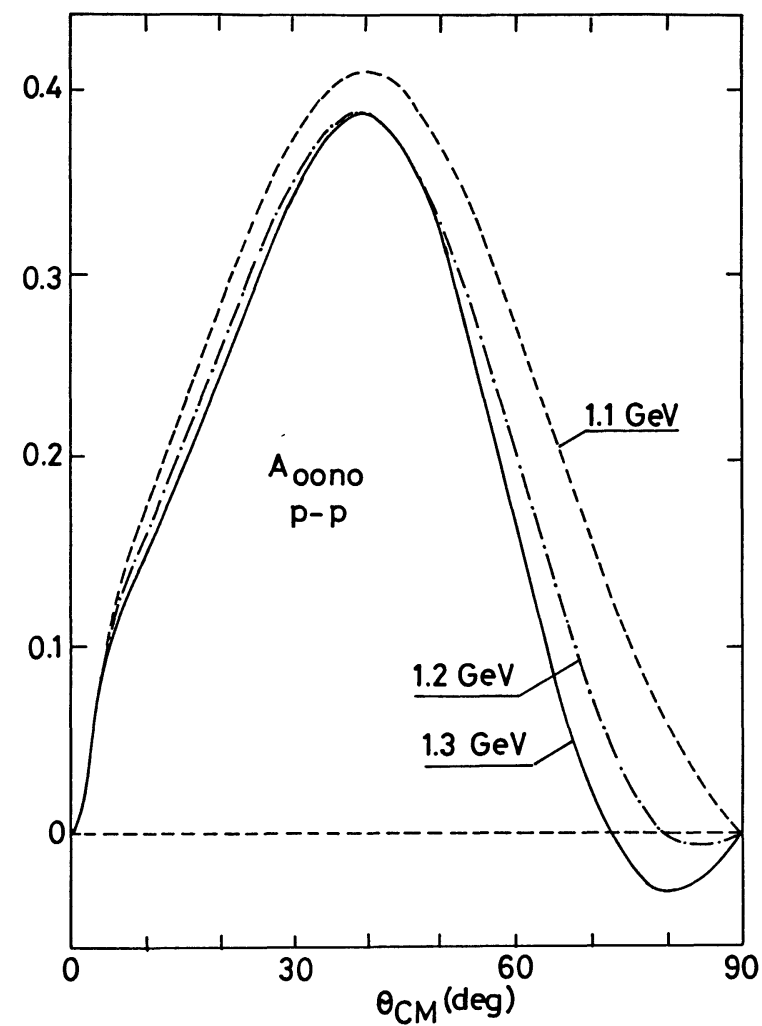

Fig. 18. - Angular dependences of $A_{\mathrm{oono}}=f\left(\theta_{\mathrm{CM}}\right)$ at 1100,1200 and $1300 \mathrm{MeV}$.

slope of the analysing power near $90^{\circ} \mathrm{CM}$ is also well described. The energy dependence of the phase shifts smoothly connects with Saclay-Geneva PSA previous results below $800 \mathrm{MeV}$. An important disagreement is observed with the results of Arndt $e t$ $a l$. for almost all phase shifts. The energy dependence of the phase shifts above $1.1 \mathrm{GeV}$ may change when the 2 and 3 spin-index data measured at Saturne II are available.

The present PSA shows the general behaviour of phase shifts and provides good predictions for the design of pp elastic and inelastic scattering experiments as well as for values of nucleon-nucleon amplitudes used as input in nucleon-nucleus scattering models. It also provides useful information about a possible resonance-like behaviour in several partial waves.

\section{Acknowledgments.}

We acknowledge J. Arvieux, R. Hess and G.

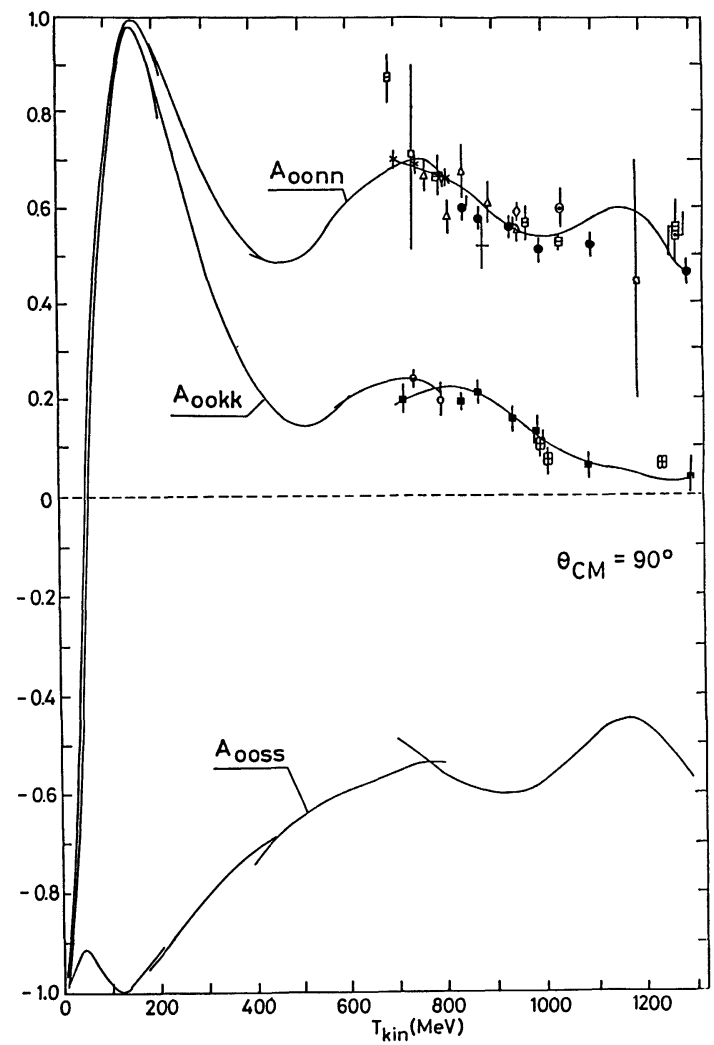

Fig. 19. - Energy dependences of the spin correlation parameters $A_{\text {oonn }}, A_{\text {ookk }}$ and $A_{\text {ooss }}$ at $\theta_{\mathrm{CM}}=90^{\circ}$. - this PSA and reference [1] ; Symbols for $A_{\mathrm{oonn}}$ : $日$ ZGSANL, reference 80/B-304/ in [2] ; $\odot$ ZGS-ANL, reference $78 / \mathrm{L}-52 /$ in [2] ; $\square$ ZGS-ANL, reference 77/M-97/ in [2] ; $\square$ Saturne I, reference 67/C-26/ in [2] ; $\nabla$ LAMPF, reference $80 / \mathrm{M}-111 /$ in [2] ; * LAMPF, reference [43] ; + Gatchina, reference [36] ; $\diamond$ Gatchina, reference [37] ; $\triangle$ Gatchina, reference [38]; - Saturne II, references [32, 45] ; Symbols for $A_{\text {ookk }}$ : O LAMPF, reference [20] ; $\nexists$ ZGS-ANL, reference [69] and reference 78/A-165/ in [2] (numerical values); $\square$ Saturne II, references [47, 48].

Smadja for their support during this work. We are much indebted to J. Ball, A. Gersten, C. D. Lac, E. Leader, A. de Lesquen, B. Loiseau, F. Perrot, W. Plessas, L. van Rossum, I. Ulehla, C. Wilkin and P. Winternitz for helpful discussions. We thank also the Nucleon-Nucleon group members at Saturne II and M. Garçon, M. M. Gazzaly, D. Legrand, A. Masaike, G. Pauletta, J. Saudinos, H. Spinka, Y. Terrien, and S. S. Yamamoto for providing us with their data before publication.

\section{References}

[1] Bystricky, J. Lechanoine-LeLuc, C. and LeHAR, F., J. Physique 48 (1987) 199.

[2] Bystricky, J. and Lehar, F., Physics Data Nr 11-1, Part I and II (1978) Nr 11-2 and 11-3 (1981), edited by H. Behrens and G. Ebel (Fachinfor- mationszentrum Karlsruhe) and Bystricky J., Carlson P., Lechanoine C., Lehar F., Monnig F., Schubert K. R., Landolt-Bornstein Tables, New Series Vol. 9a (1980), edited by H. Schopper (Springer-Verlag). 
[3] Arndt, R. A., Roper, L. D., Bryan, R. A., Clark, R. B., VerWest, B. J., Signel, P., Phys. Rev. D 28 (1983) 97 and Private communication.

[4] Arndt, R. A., BYSlop, J. S. and Roper, L. D., Phys. Rev. D 35 (1987) 128.

[5] Higuchi, Y., Hoshizaki, N., NaKaO, H. and SUZUKI, K., contributed paper to « 1983 INS Symposium », Tokyo, 1983.

[6] Vovchenko, V. G., Kazarinov, M. Yu., Kazarinov, Yu. M., Prokofiev, A. N. and StrachOtA, J., Yad. Fiz. 37 (1983) 158, transl. Sov. J. Nucl. Phys. 37 (1) (1983) 90.

[7] Grebenyuk, O. G., Komarov, E. N. and ShKLYAREVSKII, G. M., Yad. Fiz. 39 (1983) 74, transl. Sov. J. Nucl. Phys. 39 (1984) 44.

[8] Dubois, R., Axen, D., Keeler, R., Comyn, M., Ludgate, G. A., Richardson, J. R., Stewart, N. M., Clough, A. S., BugG, D. V. and Edgington, J. A., Nucl. Phys. A 377 (1982) 554.

[9] Côté, J., Lacombe, M., Loiseau, B. and CottingHAM, W. N., Nucl. Phys. A 379 (1982) 349 ;

and LACOMBe, M., Loiseau, B., Richard, J. M., Vinh MaU, R., Côté, J., Pirès, P. and DE Tourreil, R., Phys. Rev. C 21 (1980) 861.

[10] Loiseau, B., J. Physique Colloq. 46 (1984) C2-339; and Loiseau, B., Private Communication, October 1986.

[11] Bystricky, J., Lehar, F. and Winternitz, P., J. Physique 39 (1978) 1.

[12] Stapp, H. P., Ypsilantis, T. J., Metropolis, M., Phys. Rev. 105 (1957) 302.

[13] Cziffra, P., MacGregor, M. H., Moravcsik, M. J. and StAPP, H. P., Phys. Rev. 114880 (1959) ;

and MacGregor, M. H., MoravcsiK, M. J. and Stapp, H. P., Ann. Rev. Nucl. Sci. 10 (1960) 291.

[14] Hoshizaki, N., Suppl. Progr. Theor. Phys. 42 (1968) 107.

[15] Breit, G. and Ruppel, H., Phys. Rev. 127 (1962) 2123.

[16] Shimizu, F., Kubota, Y., Koiso, H., SAI, K., SaKamoto, S. and Yамамото, S. S., Nucl. Phys. A 386 (1982) 571.

[17] Perrot, F., Azaiez, H., Ball, J., Bystricky, J., Chaumette, P., Chesny, Ph., Derégel, J., FABre, J., Fontaine, J. M., Gosset, J., Lehar, F., LeO, W. R., DE LesQuen, A., Newsom, C. R., Onel, Y., Penzo, A., vaN Rossum, L., SiemiarczuK, T., VRzal, J., WhitTEN, C. A. Jr. and YonNet, J., Nucl. Phys. B 278 (1986) 881.

[18] Ditzler, W. R., Hill, D., Imai, K., Shimizu, H., SPINKA, H., STANeK, R., Toshioka, K., UNDERWOOD, D., WAGNer, R., YoKosAwA, A., Burleson, G. R., COTTINGAME, W. B., Greene, S. J., JARMER, J. J., JePPESEN, R. H., Phys. Rev. D 27 (1983) 680.

[19] Madigan, W. P., Bell, D. A., Buchanan, J. A., Calkin, M. M., Clement, J. M., Copel, M., Corcoran, M. D., JOHNS, K. A., LESIKAR,
J. D., Miettinen, J. E., Mutchler, G. S., Naudet, C. J., Pepin, G. P., Phillips, G. C., Roberts, J. B., Turpin, S. E., Hungerford, E. V., Mayes, B. W., Hancock, A. D., Pinski, L. S., SeKharan, K. K., Hollas, C. L., Riley, P. J., Allred, J. C., Bonner, B. E., CAMERON, P., LinN, T. S., VON WitsCh, W., Furic, M., Valkovic, V., Phys. Rev. D 31 (1985) 966.

[20] Auer, I. P., Ditzler, W. R., Hill, D., Imai, K., SpinKa, H., StaneK, R., TOSHIOKA, K., UNDERWOOD, D., WAGNER, R., YOKOSAWA, K., HOFFMAN, E. W., JARMER, J. J., BURLESON, G. R., Cottingame, W. B., Greene, S. J. and Stuart, S., Phys. Rev. D 29 (1984) 2435.

[21] Bystricky, J., Chaumette, P., Derégel, J., FABRE, J., Lehar, F., DE LESQUen, A., VAN Rossum, L., Fontaine, J. M., Gosset, J., Perrot, F., Ball, J., Hasegawa, T., NewSOM, C. R., YonNET, J., LEO, W. R., ONEL, Y., Penzo, A., Azaiez, H., Michalowicz, A., Phys. Lett. 142B (1984) 130.

[22] Dobrovolsky, A. V., Khanzadeev, A. V., Korolev, G. A., Maev, E. M., Medvedev, V. I., Sokolov, G. L., Terentyev, N. K., TERrien, Y., VelichKo, G. N., Vorobyov, A. A. and Zalite, Yu. K., Nucl. Phys. B 214 (1983) 1.

[23] Velichko, G. N., Vorobyov, A. A., Zalite, Yu. K., Korolev, G. A., MaEv, E. M., TerentyeV, N. K., KhanzadeeV, A. V. and SHCHEGEL'SKII, A. V., Yad. Fiz. 35 (1982) 1457 transl. Sov. J. Nucl. Phys. 35 (6) (1982) 852.

[24] Garçon, M., Legrand, D., LOMBARD, R. M., MAyer, B., Rouger, M., Terrien, Y. and NAKACH, A., Nucl. Phys. A 445 (1985) 669.

[25] Pauletta, G., Adams, G., Haji-Saied, S. M., IGo, G. J., MCClelland, J. B., WANG, A. T. M., Whitten, C. A. Jr., Wriekat, A., Gazzaly, M. M., Tanaka, N., Phys. Rev. C 27 (1983) 282.

[26] Barlett, M. L., HoffmanN, G. W., MCGill, J. A., Hoistad, B., Ray, L., Fergerson, R. W., Milner, E. C., Marshall, J. A., Amann, J. F., Bonner, B. E., MCClelland, J. B., Blanpied, J. S., ARndt, R. A., Phys. Rev. C 27 (1983) 682.

[27] Shimizu, F., Koiso, H., Kubota, I., SAI, F., SaKamoto, S. and Yамамото, S. S., Nucl. Phys. A 389 (1982) 445.

[28] Hollas, C. L., Cremans, D. J., McNaughton, K. H., Riley, P. J., Rodebaugh, R. F., SHENWu Xu, BonNer, B. E., MCNaughton, M. W., OHNuma, H., VAN Dyck, O. B., Sun TSU-Hsun, TURPIN, S., AAs, B. and Weston, G. S., Phys.Rev. C 30 (1984) 1251.

[29] McNaughton, M. W. and Chamberlin, E. P., Phys. Rev. C 24 (1981) 1778.

[30] Garçon, M., Thesis, Faculté des Sciences, Orsay, 1985 and Private Communication of Garçon M., Legrand D. and Saudinos J., Phys. Lett. B, to be published. 
[31] Bystricky, J., Chaumette, P., Derégel, J., FABRe, J., Lehar, F., DE Lesquen, A., VAN Rossum, L., Fontaine, J. M., Gosset, J., Perrot, F., Whitten, C. A. Jr., BAll, J., Chesny, P., Newsom, C. R., YonNet, J., NiINikoski, T., Rieubland, M., MichalowICZ, A., Dalla Torre-Colautti, S., Nucl. Phys. B 262 (1985) 727.

[32] Bystricky, J., Chaumette, P., Derégel, J., Fabre, J., Lehar, F., De Lesquen, A., Petit, F., Van Rossum, L., Fontaine, J. M., Perrot, F., Ball, J., Michalowicz, A., Onel, Y., Penzo, A., Nucl. Phys. B 262 (1985) 715.

[33] Ball, J., Ghazikhanian, V., GoRdon, J., LehaR, F., de Lesquen, A., Perrot, F. and VAN Rossum, L., Nucl. Phys. B 286 (1987) 635.

[34] Perrot, F., Fontaine, J. M., Bystricky, J., Chaumette, P., Derégel, J., Fabre, J., Lehar, F., Ball, J., Michalowicz, A., ONEl, Y., Aas, B., Adams, D., GhazikHanian, V., Igo, G., Sperisen, F., Whitten, C. A., Penzo, A., 7th International Symposium on High Energy Spin Physics, Protvino (USSR), 22-27 September 1986.

[35] Bystricky, J., Chaumette, P., Derégel, J., FAbre, J., Lehar, F., DE Lesquen, A., VAN Rossum, L., Fontaine, J. M., Perrot, F., Ball, J., LAC, C. D., Michalowicz, A., Onel, Y., Penzo, A., 7th International Symposium on High Energy Spin Physics, Protvino (USSR), 22-27 September 1986.

[36] Prokofiev, A. N., Rapport LIYaF, Gatchina 1984. [37] Borisov, N. S., Vovchenko, V. G., EFIMOVYCH, V. A., Zhdanov, A. A., Kazarinov, M. Yu., KaZARINOV, Yu. M., Kiselev, Yu. F., Kovalev, A. I., Liburg, M. Yu., MataFONOV, V. I., Polyakov, V. V., PoPOV, V. E., Prokofiev, A. N., Trautman, V. Yu., Usov, Yu. A., Fedorov, O. Ya., and Schvedchikov, A. V., Pisma Zh. Eksp.Teor. Fiz. 34 (1981) 137, transl. JETP Lett. 34 (1981) 130.

[38] Borisov, N. S., Vovchenko, V. G., EFimovych, V. A., Zhdanov, A. A., Kazarinov, M. Yu., KaZARINOV, Yu. M., KISElev, Yu. F., Kovalev, A. I., Liburg, M. Yu., Neganov, B. S., Polyakov, V. V., Popov, V. E., ProKofiEv, A. N., Trautman, V. Yu., Usov, Yu. A., Fedorov, O. Ya., and SchVEDCHIKov, A. V., Zh. Eksp. Teor. Fiz. 81 (1981) 1583, transl. Sov. Phys. JETP 54 (5) (1981) 841.

[39] Hollas, C. L., Cremans, D. J., Ransome, R. D., Riley, P. J., BonNer, B. E., MCNaughton, M. W. and Wood, S., Phys. Lett. 143B (1984) 343.

[40] Barlett, M. L., Hoffmann, G. W., McGill, J. A., Fergerson, R. W., Milner, E. C., Marshall, J. A., AMANN, J. P., BonNer, B. E. and MCClelland, J. B., Phys. Rev. C 30 (1984) 279.

[41] McNaughton, M. W., Bonner, B. E., Cornelius, W. D., Hoffman, E. W., VAN DYCK, O. B., YoRK, R. L., RANSOME, R. D., Hollas, C. L.,
Riley, P. J., Toshioka, K., Phys. Rev. C 25 (1982) 1967.

[42] Borisov, N. S., VovchenKo, V. G., EFIMOVYCH, V. A., ZhDanov, A. A., Kazarinov, Yu. M., Kiselev, Yu. F., Kovalev, A. I., Kozlenko, N. G., Miakushkin, M. Yu., Polyakov, V., Popov, V. E., Trautman, V. V., Fedorov, O. Ya., CheRniKov, A. N., SCHVEDCHIKOV, A. V., JETP Lett. (USSR) 43 (1986) 559, transl. JETP Lett. 43 (1986).

[43] Bhatia, T. S., Glass, G., Hiebert, J. C., Kenefick, R. A., NorthCliffe, L. C., TiPPENS, W. B., BoIsSEVVAIN, J. G. J., JARMER, J. J., Simmons, J. E., Tripard, G. E., FitzGERALD, D., HOLT, J. and MOKHTARI, A., Phys. Rev. Lett. 49 (1982) 1135.

[44] Pauletta, G., Private Communication Feb. 1985 and Gazzaly M. M., Private Communication, Nov. 1985.

[45] Bystricky, J., Chaumette, P., Derégel, J., Fabre, J., Lehar, F., De Lesquen, A., Van Rossum, L., Fontaine, J. M., Perrot, F., Ball, J., Michalowicz, A., Onel, Y., Aas, B., Adams, D., Ghazikhanian, V., Igo, G., SPerisen, F., Whitten, C. A., Penzo, A., 7th International Symposium on High Energy Spin Physics, Protvino (USSR), 22-27 September 1986.

[46] Auer, I. P., Colton, E., Ditzler, W. R., Hill, D., Miller, R., SpinKa, H., Theodosiou, G., TAVERnier, J.-J., TAMURA, N., TOSHIOKA, K., UNDERWOOD, D., WAGNER, R., YOKOSAWA, A., Kroll, P. and JAUCH, W., Phys. Rev. Lett. 51 (1983) 1411.

[47] Bystricky, J., Chaumette, P., Derégel, J., FABRE, J., LeHAR, F., DE Lesquen, A., VAN Rossum, L., Fontaine, J. M., Perrot, F., Ball, J., Hasegawa, T., Newsom, C. R., Penzo, A., Azaiez, H., Michalowicz, A., Nucl. Phys. B 258 (1985) 483.

[48] Bystricky, J., Chaumette, P., Derégel, J., Fabre, J., Lehar, F., De LesQuen, A., VAN Rossum, L., Fontaine, J. M., Perrot, F., Ball, J., LAC, C. D., Michalowicz, A., GHAZIKHANiAN, V., 7th International Symposium on High Energy Spin Physics, Protvino (USSR), 22-27 September 1986.

[49] Lehar, F., SiemiarCZUK, T., Winternitz, P. and BYSTRICKY, J., Preprint, DPhPE 79-28, Saclay 1979.

[49b] Bystricky, J., La France, P., Lehar, F., PerROT, F., SiemiarczuK, T., WinTERnitz, P., Preprint DPhPE 87-03, Saclay 1987, to be published in $J$. Physique $\mathrm{n}^{\circ} 10$ (Paris).

[50] VerWest, B. J. and Arndt, R. A., Phys. Rev. C 25 (1982) 1979.

[51] ARndt, R. A. and MACGregor, M. H., Meth. Comp. Phys. 6 (1966) 263.

[52] Puzikov, L. D., RYNDIN, R. M. and SMORODINSKII, Ya. A., Zh. Eksp. Teor. Fiz. 32 (1957) 592, transl. Sov. Phys. JETP 5 (1957) 489.

[53] KlepiKov, N. P., Zh. Eksp. Teor. Fiz. 47 (1964) 757, transl. Sov. Phys. JETP 20 (1965) 505. 
[54] Bystricky, J., Lehar, F. and Winternitz, P., [64] Lehar, F. and Winternitz, P., Fortschritte Phys. 15 Experientia Suppl. 25 (1976) 462.

[55] Bystricky, J., LehAR, F., PATERA, J. and WinTERNITZ, P., Lecture Notes Phys. 87 (1978) 509.

[56] La France, P. and Winternitz, P., Phys. Rev. D 27 (1983) 112.

[57] Goldstein, G. R., MoravcsiK, M. J., NIM 227 (1984) 108.

[58] Aprile, E., Eisenegger, C., Hausammann, R., HeEr, E., Hess, R., Lechanoine-Leluc, C., LeO, W. R., Morenzoni, S., Onel, Y. and RAPIN, D., Phys. Rev. Lett. 46 (1981) 1047.

[59] LeChanoine-Leluc, C., Invited Talk to 7th International Symposium on High Energy Spin Physics, Protvino (USSR), 22-27 September 1986.

[60] Bystricky, J., Lehar, F. and Winternitz, P., Preprint CRM-763, Université de Montréal, Montréal, 1978 and J. Physique Lett. 40 (1979) L 117.

[61] KlePIKov, N. P., Zh. Eksp. Teor. Fiz. 41 (1961) 1187, transl. Sov. Phys. JETP 14 (1962) 846.

[62] KlePIKov, N. P., Zh. Eksp. Teor. Fiz. 44 (1963) 376, transl. Sov. Phys. JETP 17 (1963) 269.

[63] Klepikov, N. P., SMORODINSKII, Ya. A., Zh. Eksp. Teor. Fiz. 43 (1962) 2173, transl. Sov. Phys. JETP 16 (1963) 1458.

(1967) 495.

[65] Lomon, E. L., Aussois Meeting, March 1980 and Private Communication (1984).

[66] Kroll, P., Phenomenological Analyses of NucleonNucleon Scattering, Physics Data $\mathrm{Nr} 22-1$ (1981), edited by H. Behrens and G. Ebel (Fachinformationszentrum Karlsruhe).

[67] Stanley, J. P., Stewart, N. M., Bugg, D. V., Edgington, J. A., SteVEnSON, N. R., Clough, A. S., Axen, D. A., Shypit, R., Comyn, M., Healey, D. and Ludgate, G. A., Nucl. Phys. A 403 (1983) 525.

[68] Aprile-Giboni, E., Bystricky, J., Derégel, J., Drompt, Ph., EISENEgGer, C., Fontaine, J. M., HeER, E., Hess, R., JACCARD, S., Lehar, F., LeO, W. R., MANGo, S., MORENzoni, S., Onel, Y., Perrot, F., Rapin, D., VrZal, J. and Yonnet, J., Nucl. Phys. A 431 (1984) 637.

[69] Auer, I. P., Beretvas, A., Colton, E., Halpern, H., Hill, D., Nield, K., SANDler, B., SPINKA, H., THEOdosiou, G., UNDERWOOD, D., Watanabe, Y. and Yokosawa, A., Phys. Rev. Lett. 41 (1978) 1436. 